Working Paper

Series
${ }_{1}$ IIIIIFINRISK

National Centre of Competence in Research Financial Valuation and Risk Management

National Centre of Competence in Research

Financial Valuation and Risk Management

Working Paper No. 406

\title{
The Earnings Game with Behavioral Investors
}

Kremena Bachmann

First version: February 2007

Current version: February 2007

This research has been carried out within the NCCR FINRISK project on

"Behavioural and Evolutionary Finance" 


\title{
The Earnings Game with Behavioral Investors*
}

\author{
Kremena Bachmann ${ }^{\dagger}$ and Thorsten Hens ${ }^{\ddagger}$
}

February 2007

\begin{abstract}
This paper studies how the investors' attitude towards earnings surprises affects the managers' incentives to manipulate earnings in an intertemporal context, where the consensus forecast of the analysts is not exogenously given but determined by the strategic interaction between the analysts and the managers. Our analysis shows that given the asymmetric investors' reaction to earnings surprises, managers have strong incentives to manipulate earnings. In dependence on their time preferences, managers may choose to manipulate the earnings in order to match the consensus forecasts. In this equilibrium, rational investors are systematically fooled. Assuming that managers' preferences are equally distributed in the economy, we also derive conclusions on how the absolute level of manipulation in the economy changes with the investors' preferences, the managers' compensation package and the earnings guidance they may provide to analysts.
\end{abstract}

Keywords: earnings management, loss aversion, disclosure policy

JEL Classification: G38, M21, C70

${ }^{*}$ We are grateful to Anke Gerber and the participants of the URPP Finance and Financial Markets for valuable comments. Financial support by the National Center of Competence in Research "Financial Valuation and Risk Management" (NCCR-FINRISK) is gratefully acknowledged. The national centers in research are managed by the Swiss National Science Foundation on behalf of the federal authorities

${ }^{\dagger}$ University of Zurich, Swiss Banking Institute, Plattenstrasse 32, 8032 Zurich, Switzerland, kremena@isb.unizh.ch

${ }^{\ddagger}$ University of Zurich, Swiss Banking Institute, Plattenstrasse 32, 8032 Zurich, Switzerland, thens@isb.unizh.ch 


\section{Introduction}

Each quarter, the attention of the investors' community is drawn to the earnings numbers reported by public companies. However, these numbers themselves are of much less relevance than their value relative to certain benchmarks.

The main benchmarks investors use are the previous earnings (Burgstahler and Dichev, 1997) and the analysts' consensus forecast (Degeorge, Patel, and Zeckhauser, 1999; Brown, 2001, and Matsumoto, 1999; Freeman and Tse, 1992). Compelling empirical evidence suggests that firms falling short of the benchmarks are priced at a discount, which is larger in absolute terms than the premium the firms get when they report earnings above the benchmark (Kasznik and McNichols, 2002; Bartov, Givoly and Hayn, 2002; Skinner and Sloan, 2002). Ultimately, executives seem also to believe that hitting earnings benchmarks strengthens their creditability, helps increasing their companies' stock price (Graham, Harvey, and Rajgopal, 2005) as well as their compensation (Matsunaga and Park, 2001).

Given the empirical evidence on the relevance of benchmarks, we analyze the question how the asymmetric price response to meeting and falling short of the benchmarks affects the reporting decision of the managers. Assuming that the benchmarks are exogenously given, previous studies conclude that the observed patterns in the managers' reporting are due to earnings management. However, it is not clear whether managers' incentives to manipulate earnings remain unchanged when this assumption does not hold. In particular, it is ambiguous whether and how managers would manipulate earnings when the analysts behave strategically when playing the earnings game.

To answer this question, we propose a three-period model with a manager, analysts and investors endowed with behavioral preferences. We show that when the manager and the analysts behave strategically, the manager's incentives to manipulate earnings change as a response to the investors' preferences defining the market conditions, the manager's compensation package and the manager's guidance provided to analysts. In particular, our results suggest that given the asymmetric investors' reaction to earnings surprises, the manager strongly prefers to manipulate earnings than to report truthfully independently of her compensation package. If the manager is roughly indifferent between selling shares in the current or later periods, she manipulates the earnings in order to meet the analysts forecasts. In this equilibrium rational investors are systematically fooled. In all other cases, investors are able to reverse the manager's manipulation so that the reporting decision of the manager depends strictly on her time preferences. Assuming that manager's preferences are equally distributed in the economy, we also derive conclusions on how the absolute level of manipulation in the economy changes with the investors' preferences, the manager's compensation and the earnings guidance she may provide to analysts. Our results suggest that whatever the manager's compensation there will be less manipulation in absolute terms when investors have behavioral preferences. The absolute level of manipulation may also decrease if the manager are compensated with stock options instead of shares independently on the investor's preferences. However, if investors are non-behavioral and the managers holding stock options provide earnings guidance, i.e anticipates the action of the analysts to their earnings reports, the absolute manipulation level in the economy would increase compared to the no-guidance case. 
In our framework, the manager's decision to manipulate earnings is a matter of an inter-temporal substitution. The manager may shift revenues from one year to another at costs determined by the investors and in particular by their preferences with respect to earnings reports.

Previous research on the question why managers manipulate earnings reports provides other explanations. Using the idea that earnings management is costly, Chaney and Lewis (1994) show that managers manipulate earnings to signal their ability to generate value. By smoothing reporting earnings around the "expected" earnings report, high-value managers can increase the probability that investors identify their ability of generating value correctly. On the other hand, if low-value managers realize that the costs of misreporting exceeds the benefits of being identified as a high-value firm, then the earnings signals of the firms can be perfectly informative in equilibrium. Instead of manipulating earnings in order to make investors believe the firm is more valuable, Trueman and Titman (1989) show that firms manipulate earnings because they want investors to perceive the firm as less risky. According to their model, lower-quality firms mimic higher-quality firms by smoothing the earnings reports, which lowers the investors' assessment of the probability of bankruptcy. Managers may also manipulate earnings because investors are unable to observe the manager's objectives and adjust to the bias added to the earnings reports. The manager's optimal level of manipulation is then determined by the trade-off between some costs of earnings management and the benefit of higher stock price resulting from higher reported earnings (see Fischer and Verrecchia, 2000). This idea is also used by Guttman, Kadan and Kandel (2004) in order to explain why earnings reports are discontinuous around some thresholds. By hiding some of their private information in a pooled report managers with different economic earnings are able to increase their payoff by reducing the costs of earnings manipulation. Further, firm's earnings management choice may also be driven by the choices made by its rivals. If a firm is compared by investors and creditors with other firms in the same industry, it would manage its earnings simply because it expect its rivals to do so (see Bagnoli and Watts, 2000). Finally, Stein (1989) suggests that earnings management occurs if managers are myopic. The conclusion rests basically on the assumption that investors form expectations based on the noise in the earnings signals but not on the level of earnings relative to certain thresholds.

The importance of thresholds is, however, emphasized in several empirical studies. Barth, Elliott, and Finn (1999) find that firms that report continuously growing earnings are priced at a premium to other firms and the premium increases with the length of the string. Myers and Skinner (2001) find that managers of such firms usually have relatively large amount of personal wealth invested in the company providing them with incentives to extend the earnings string making accounting choices that avoid reporting adverse earnings.

The relevance of the consensus forecast is highlighted by other studies. Kasznik and McNichols (2002) find that firms which meet expectations receive a higher market value than firms that fail to meet the expectations. Although they additionally conjecture that firms consistently meeting the consensus do so through strong earnings, they cannot exclude the possibility that firms could meet expectations by earnings manipulation and investors may fail to anticipate this. In a recent study, Degeorge, Patel and Zeckhauser (2006) investigate the price response to earnings reports meeting the consensus forecast over time. 
They find that firms meeting or exceeding earnings thresholds experience economically and statistically significant excess returns, which are particularly high in a bull market. Their results motivate them to conjecture that investors seem to view earnings threshold attainment as an important indicator of the health of the company, which encourage the managers to manipulate earnings. To test the benefits from earnings manipulation, Bartov, Givoly and Hayn (2002) examine the manner by which earnings management contributes to the premium that firms receive when they meet or beet earnings expectations. They confirm that firms receive a premium if they manage to meet or beet the consensus forecast and show, in addition, that investors are capable to discern the effect of earnings management on the earnings surprise and discount the resulting surprise, but the extent of this discount is small and not economically significant. Further, Skinner and Sloan (2002) show that the stock price response to falling short of the analysts expectations is disproportionately large for growth stocks.

Our research contributes the literature on earning management in several ways. First, we extent the theoretical literature by studying a three-period strategic game between a manager and the analysts rather than a one-shot disclosure choice of different firms involved in a signaling game with other competitors. That is, instead of assuming that there are high- and low-value firms manipulating earnings to pool their reports, we use the empirical evidence that investors value earnings reports with respect to thresholds to study the manager's manipulation incentives in a setting where the threshold is not exogenously given but defined by analysts behaving strategically. Thus, the focus of our study is not the managers' incentives to manipulate earnings when playing a game with other managers endowed with private information regarding their value as in the signaling literature. Instead we focus on the manager's incentives to manipulate earnings when the manager is involved in a strategic game with the analysts. Whereas the signaling literature assumes that the differences in the managers' type motivating earnings manipulation are exogenously given, we specify the analysts' response representing a threshold for the value of earnings reports endogenously.

Second, by studying manager's manipulation incentives when her payoff is defined by behavioral investors we contribute to the general discussion on the economic relevance of investors' preferences for earnings reports that are at or above the target defined by the analysts. Some empirical studies have already hypothesized that this investors' attitude motivate managers to manipulate earnings in order to meet the targets (see for example Degeorge, Patel, Zeckhauser, 1999). However, they did not explicitly considered the possibility that analysts may be fairly aware of their role as target setters, which again may change the manager's motivation to manipulate earnings.

Finally, our analysis contribute to the literature dealing with the definition of regulatory standards. By studying a simple economy where the managers' time preferences are equally distributed, we derive conclusions on how the absolute level of manipulation in that economy change with the investors' preferences, the managers' compensation package and the earnings guidance provided by managers to analysts.

This paper is organized as follows. The next section describes the information structure of the game and the decision processes of the manager, the investors and the analysts. Section 3 defines the players of the game, their strategy sets and payoffs. It also defines the game equilibria. The players' strategies 
in equilibrium are studied in section 4 . The analysis is structured in three parts. The first part considers the managers' incentives to manipulate earnings when managers hold stock options and play the earnings game with behavioral and non-behavioral investors. The second part studies the managers' incentives to manipulate earnings, when they hold stock options instead of shares and play the earnings game with behavioral and non-behavioral investors. The third part analyzes how the manager decide on earnings manipulation when she provide earnings guidance to analysts. The main results as well as the implications of the market conditions, the manager's compensation and the manager's guidance on the absolute level of manipulation in the economy are summarized in section 5 .

\section{Information Structure and Decision Timing}

We consider a three-period economy with one firm, analysts and a large number of investors. The firm is controlled by a manager. The information structure and the decision order of the agents in the economy are summarized as follows.

\begin{tabular}{lll}
$t-1$ & $t$ & $t+1$ \\
\hline & & \\
1. Analysts: $F_{t}$ & 1. Nature: $x_{t}$ & 1. Nature: $x_{t+1}$ \\
& 2. Manager: $D_{t}$ & 2. Manager: $D_{t+1}$ \\
& 3. Analysts: $F_{t+1}$ & 3. Investors: $P_{t+1}, C_{t+1}$ \\
& 4. Investors: $P_{t}, C_{t}$
\end{tabular}

In period $t-1$, the analysts make forecasts on the earnings that will be reported by the manager in period $t$. The average of their forecasts in this period, i.e. the consensus forecast, is denoted by $F_{t}$.

At the beginning of period $t$, nature chooses which state of "true" earnings $x_{t} \in\{\underline{x}, \bar{x}\}$ realizes. All agents in the economy agree that the probability for observing $\bar{x}$ is $p$ and the probability for observing $\underline{x}$ is respectively $1-p$. The "true" earnings are also assumed to be common knowledge, so that the firm's outsiders know the moments of the "true" earnings distribution. However, only the manager is able to observe which state of "true" earnings realizes in each period.

After observing $x_{t}$ and $F_{t}$, the manager decides whether and how to manipulate earnings. In dependence on the state of "true" earnings and the manipulation decision of the manager, earnings reports in period $t$ are $D_{t}=\left(\bar{D}_{t}, \underline{D}_{t}\right)$, where $\bar{D}_{t}=\bar{x}_{t}+\bar{m}$ and $\underline{D}_{t}=\underline{x}_{t}+\underline{m}$, with $\bar{m}$ as the manipulation decision of the manager given that $x_{t}=\bar{x}$, and $\underline{m}$ as the manipulation decision of the manager given that $x_{t}=\underline{x}$. We assume that the manager's discretion to manipulate earnings is limited by certain bounds, i.e. $\bar{m}, \underline{m} \in\left[m_{\min }, m_{\max }\right]$, where $m_{\max }>0$ and $m_{\min }<0$. That is, the manager is allowed to inflate or deflate earnings but her report cannot be too far away from the "true" earnings, otherwise the auditors would not accept it. For simplicity we assume that $\left|m_{\max }\right|=\left|m_{\min }\right|$. The bounds in our setting are common knowledge.

The analysts use the manager's report $D_{t}$ to update their beliefs regarding the next period earnings the manager will be able to report. The consensus forecast is captured by $F_{t+1}$. Depending on the observed earnings in period $t$, i.e. $\bar{D}_{t}$ or $\underline{D}_{t}$, the consensus forecast for the earnings reported in $t+1$ are 
denoted by $\bar{F}_{t+1}$ respectively $\underline{F}_{t+1}$. The analysts communicate their updated expectations to investors and they respond by adjusting the price of the firm's shares $P_{t}=\left(\bar{P}_{t}, \underline{P}_{t}\right)$, which returns the value of the firm's stock options $C_{t}=$ $\left(\bar{C}_{t}, \underline{C}_{t}\right)$. In our notation, $\bar{P}_{t}\left(\underline{P}_{t}\right)$ is the price of the firm's shares and $\bar{C}_{t}\left(\underline{C}_{t}\right)$ captures the value of the firm's stock options in period $t$ given that $x_{t}=\bar{x}$ $\left(x_{t}=\underline{x}\right)$ and $D_{t}=\bar{D}_{t}\left(D_{t}=\underline{D}_{t}\right)$.

In the last period, nature draws the "true" earnings $x_{t+1} \in\{\bar{x}, \underline{x}\}$. In this period, we assume that the manager does not make any decisions. His reporting is defined by the "true" earnings realizing in this period and the manipulation decision taken one period before. This is consistent with accounting standards such as GAAP requiring that any discretionary element in reported earnings must be eventually reversed over time so that at the end of the game, there is no manipulation remained in the economy and the accumulated reported earnings reported are equal to the accumulated "true" earnings. We operationalize this institutional requirement through a GAAP constrained requiring that the bias added in the period $t$ is reversed in the next one. The earnings reports in the last period are then $D_{t+1}=(\bar{x}-\bar{m}, \bar{x}-\underline{m}, \underline{x}-\bar{m}, \underline{x}-\bar{m})$ with $x_{t+1} \in\{\bar{x}, \underline{x}\}$.

Given the reported earnings $D_{t+1}=(\bar{x}-\bar{m}, \bar{x}-\underline{m}, \underline{x}-\bar{m}, \underline{x}-\bar{m})$ and the consensus forecast $F_{t+1}=\left(\bar{F}_{t+1}, \underline{F}_{t+1}\right)$, the investors determine the price of the company's shares $P_{t+1}=\left(\bar{P}_{t+1}, \underline{P}_{t+1}\right)$ where $\bar{P}_{t+1}$ is the price of firm's shares given that $x_{t}=\bar{x}$ respectively $D_{t}=\bar{D}_{t}$ and $\underline{P}_{t+1}$ is the price of firm's shares given that $x_{t}=\underline{x}$ respectively $D_{t}=\underline{D}_{t}$.

The players' actions in each state are summarized in the following figure.

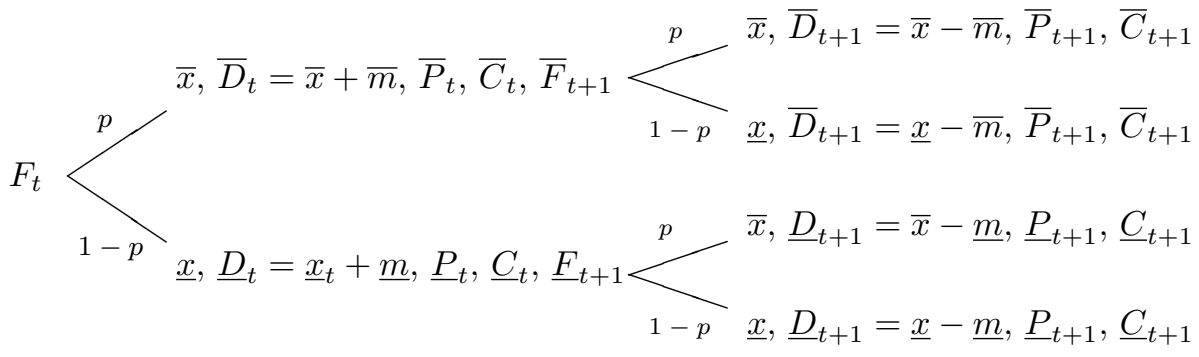

The order of events in our model is specified to be as realistic as possible. Alternative designs are also conceivable. For example, the analysts may need some time to issue the next period forecast, so that the immediate price response of the investors in period $t$ does not include the expectations of the analysts. Alternatively, the analysts may issue several forecasts in the period $t$ so that each time the investors need to adjust their expectations and the price of firm's shares. These alternative decision designs do not affect our results given that all firm's outsiders share the same expectations regarding the next period reporting earnings.

\subsection{The Investors}

From the manager's perspective, the investors represent a homogenous group that determines the price of the firm's shares using all available information efficiently. In line with the empirical evidence (see for example Kasznik and 
McNichols, 2002; Skinner and Sloan, 2002; Kinney et. al., 2001), we assume that the price response to deviations from the consensus earnings forecast is asymmetric. Investors reward companies for meeting or beating analysts' earnings expectations but penalize them stronger for falling below this target independently of the firm's absolute performance. In models with asymmetric information, the reason underlying this price response is the apparent information content in earnings surprises regarding the future earnings potential of the firm. In this context, earnings manipulation is a signaling device. In our model, the main driver for a manager deciding on her reporting strategy is not her private information. Instead, we attempt to explain manager's decisions by the preferences of the investors while imposing minimal restriction on the distribution of information among the agents in the economy. In particular, we assume that investors are averse against negative earnings surprises because from their perspective, the consensus forecast represents a reference point against which investors judge earnings announcements and determine ultimately the value of the company.

At least since the contribution of Kahneman and Tversky (1979), the importance of reference points became one of the main issues of research on decision making under uncertainty. One of their core findings is that the disutility from a loss looms greater than the utility from a similar gain. Kahneman and Tversky call this property loss aversion. We use the idea that investors may be loss averse when evaluating the earnings reported by the company to model the price response to earnings reports.

In our setting, the price of the firm's shares is determined by two factors. The first is the present value of the firm's earnings reported at the end of each period. The second factor is a premium (or discount) for meeting (falling short of) investors' expectations. Formally, the market value of the firm's shares in period $t$ respectively $t+1$ can be written as:

$$
P_{t}=D_{t}+\delta \mathbb{E}_{t}^{I} D_{t+1}+v\left(D_{t}-F_{t}\right)
$$

and

$$
P_{t+1}=D_{t+1}+v\left(D_{t+1}-F_{t+1}\right)
$$

where $\delta=\frac{1}{1+r}$ is the discounting rate and $r$ is the interest rate representing the time value of money. $F$ is the consensus earnings forecast. $\mathbb{E}^{I}$ represents the investors' expectations, which are assumed to be equivalent to the expectations of the analysts $\mathbb{E}^{A}$.

The function $v($.$) is the value function proposed by Kahneman and Tver-$ sky (1979) describing individual behavior under uncertainty. We use the idea that investors may be loss averse when evaluating the earnings reported by the company and specify the function $v$ as follows:

$$
v(\Delta)=\left\{\begin{array}{cc}
\Delta & \text { for } \Delta \geq 0 \\
\beta \Delta & \text { for } \Delta<0
\end{array}\right.
$$

In our setting, $\Delta$ is the earnings surprise in each period, i.e. $\Delta_{t}=D_{t}-F_{t}$ and $\Delta_{t+1}=D_{t+1}-F_{t+1}$. The parameter $\beta>1$ represents the investors' loss aversion. The higher the loss aversion, the stronger is the investors' disutility from a negative earnings surprise and the lower would be the price of the company's shares in this period. In our setting the loss aversion parameter $\beta>1$ reflects 
the asymmetry in the earnings response function observed in empirical studies, e.g. by Kinney et.al. (2001).

\subsection{The Managers}

The manager of the firm is responsible for the earnings reported at the end of each period. The manager chooses her earnings report in order to maximize the expected utility, which is specified as a function of the price of firm's shares in period $t$ and $t+1$, i.e.

$$
u_{M}\left(P_{t}, P_{t+1}, \theta\right)=(1-\theta) g\left(P_{t}\right)+\theta \delta \mathbb{E}_{t}^{M} g\left(P_{t+1}\right)
$$

$\mathbb{E}^{M}($.$) represents the manager's expectations, 0 \leq \theta \leq 1$ is a factor determining the relative importance of the market price of firm's shares in period $t$ and $t+1$ from the manager's perspective and $g($.$) is a function describing the de-$ pendence of the manager's payoff on the price of the firm's shares. Note that the manager's objective function includes only direct monetary consequences of earnings manipulation. Although including punishments for earnings manipulation and other external payments may be realistic, their consideration would be arbitrary.

There are a number of reasons why the manager might be interested in the market price of the firm's shares. One reason is the manager's compensation. If it is based on shares, the manager can sell them in period $t$ and (or) in period $t+1$ as a response to some liquidity needs for example. If the manager holds shares, the function $g($.$) is linear and \theta$ represents the percentage of shares that the manager prefers to carry over from period $t$ to period $t+1$. Alternatively, manager's interests may be linked to the price of the firm's shares if the manager's compensation package contains stock options. In this case the function $g($.$) is non-linear and 1-\theta$ is the percentage of options that the manager is allowed to exercise in period $t$ respectively the percentage of options that expire in period $t$.

In the following analysis we assume that $\theta$ represent the percentage of shares or stock options that the manager desires to carry over to the next period according to her time preferences. It is also realistic to assume that the manager's time preferences are private knowledge.

Finally, we assume that all earnings are paid as dividends at the end of each period. There are no investments or share repurchases, and the company is all-equity financed.

\subsection{The Analysts}

Empirical evidence suggests that the career advancement of the analysts is closely linked to the accuracy of their predictions (see for example Hong and Kubik, 2003). Since "true" earnings are observable only by the firm's manager, the performance of the analysts can only be measured against the earnings reported by the manager. Thus, the incentive of the average analyst is to provide a forecast that is as close as possible to the reported rather than to the "true" earnings. In particular, we assume that the earnings forecasts of the average analyst are determined by a quadratic loss function.

$$
L^{A}\left(F_{t}, F_{t+1}\right)=-\mathbb{E}_{t-1}^{A}\left(F_{t}-D_{t}\right)^{2}-\mathbb{E}_{t}^{A}\left(F_{t+1}-D_{t+1}\right)^{2}
$$


where $\mathbb{E}^{A}$ represents the expectations of the average analysts.

\section{The Earnings Game}

The analysts are aware that their forecasts may affect the earnings reported by the manager since the consensus forecast is used by investors as a target when evaluating the value of firm's shares based on the earnings reports. On the other hand, the manager knows that analysts' consensus forecast affecting the price of the firm's shares and stock options depends on her reporting. Thus, one can expect that the manager and the analysts behave strategically when deciding what earnings numbers to report respectively to forecast.

To describe the situation in which the manager and the analysts act in a setting of strategic interpendence we define the game $\Gamma=\left[I=\{M, A\},\left\{S^{M}, S^{A}\right\},\left\{U^{M}, U^{A}\right\}\right]$ where $I$ denotes the players in the game, $S^{M}$ is the strategy space of the manager, $S^{A}$ is the strategy space of the average analyst, $U^{M}$ denotes the manager's payoff function and $U^{A}$ is the payoff function of the average analyst.

In our setting the players of the game include the manager of the firm and the analysts estimating the earnings of the company announced at the end of each reporting period. The investors determine the market price of the firm's shares but they do not behave strategically. Their expectations can be regarded as equivalent to the expectations of the average analyst. ${ }^{1}$

In our setting, firm's outsiders are required to make decisions under asymmetric information. Since they are not able to observe which state of "true" earnings has been realized in the previous period, they cannot determine the manipulation included in the earnings reported by the manager. This information is however essential for the next period earnings reports expected by firm's outsiders because they know that any manipulation done in period $t$ is reversed in period $t+1$.

The expected manipulation of firm's outsiders is determined by the level of manipulation and the probability that the manager has manipulated the earnings in this way. We denote the level of manipulation expected by the firm's outsiders as $n=(\bar{n}, \underline{n})$, where $\bar{n}(\underline{n})$ is the manipulation conjecture of the firm's outsiders given that $x_{t}=\bar{x}\left(x_{t}=\underline{x}\right)$. Thus, when estimating the probability that the manager has manipulated the earnings reports by $\bar{n}$ respectively $\underline{n}$, firm's outsiders estimate the probability that nature has drawn $\bar{x}$ respectively $\underline{x}$. The prior probability for $x_{t}=\bar{x}$ is $p$. The posterior belief of the firm's outsiders after that $x_{t}=\bar{x}_{t}$ after observing $D_{t}$ is denoted by $\mu\left(\bar{x} \mid D_{t}\right)$. We assume that the posterior beliefs are formed by Bayes rule, i.e.

$$
\mu\left(\bar{x} \mid D_{t}\right)=\frac{p\left(D_{t} \mid \bar{x}\right) p}{p\left(D_{t} \mid \bar{x}\right) p+p\left(D_{t} \mid \underline{x}\right)(1-p)}
$$

where $p\left(D_{t} \mid \bar{x}\right)$ is the conditional probability for observing $D_{t}$ given that $x_{t}=\bar{x}$ and $p\left(D_{t} \mid \underline{x}\right)$ is the conditional probability for observing $D_{t}$ given that $x_{t}=\underline{x}$. For example, if $\bar{D}_{t}=\underline{D}_{t}=D_{t}$ then $\mu\left(\bar{x} \mid D_{t}\right)=p$ and if $\bar{D}_{t} \neq \underline{D}_{t}$ then $\mu\left(\bar{x} \mid D_{t}\right)=$ 1 if $x_{t}=\bar{x}$ and $\mu\left(\bar{x} \mid D_{t}\right)=0$ if $x_{t}=\underline{x}$.

\footnotetext{
${ }^{1}$ In addition to providing earnings forecasts analysts are required to issue detailed reports with their private information regarding the earnings prospects of the firms they cover. As non-strategic players, investors are assumed to trust the information provided by the informed party and adjust the price of the firm's shares accordingly.
} 
Overall, the payoff of the analysts is maximal if they can "read" behind the earnings numbers. This is possible if they know the possible manipulation actions of the manager and estimate the probability for these actions correctly. In equilibrium, the analysts' conjecture on the level of manipulation $n=(\bar{n}, \underline{n})$ must be correct. Thus, in equilibrium analysts' forecast errors occur only if the analysts updating their beliefs rationally are unable to distinguish which state of "true" earnings has been realized, i.e. if they cannot distinguish whether the manager has manipulated earnings up or down.

The strategies available to the analysts are given by the consensus forecast in each period $S^{A}=\left(F_{t}, F_{t+1} \mid F_{t} \in \mathbb{R}, F_{t+1}=\left(\bar{F}_{t+1}, \underline{F}_{t+1}\right)\right)$ where $\bar{F}_{t+1}$ is the analysts' consensus forecast for $D_{t+1}$ given that $D_{t}=\bar{D}_{t}=\bar{x}+\bar{n}$ and $\underline{F}_{t+1}$ is the analysts' consensus forecast for $D_{t+1}$ given that $D_{t}=\underline{D}_{t}=\underline{x}+\underline{n}$.

Using this notation and considering the information structure of the game, the payoff of the analysts (5) is redefined as a function of the expected loss in period $t$ and $t+1$ as follows:

$$
U^{A}\left(F_{t}, D_{t}, F_{t+1}, D_{t+1}\right)=f\left(L^{A}\left(F_{t}\right), L^{A}\left(F_{t+1}\right)\right)
$$

where

$$
L^{A}\left(F_{t}, D_{t}\right)=-p\left(\bar{D}_{t}-F_{t}\right)^{2}-(1-p)\left(\underline{D}_{t}-F_{t}\right)^{2}
$$

and

$$
L^{A}\left(F_{t+1}, D_{t+1}\right)=-p\left(\bar{D}_{t+1}-F_{t+1}\right)^{2}-(1-p)\left(\underline{D}_{t+1}-F_{t+1}\right)^{2}
$$

with

$$
\begin{aligned}
\bar{D}_{t} & =\bar{x}+\bar{n} \\
\underline{D}_{t} & =\underline{x}+\underline{n} \\
\bar{D}_{t+1} & =\bar{x}-\left[\mu\left(\bar{x} \mid D_{t}\right) \bar{n}+(1-\mu)\left(\bar{x} \mid D_{t}\right) \underline{n}\right] \\
\underline{D}_{t+1} & =\underline{x}-\left[\mu\left(\bar{x} \mid D_{t}\right) \bar{n}+(1-\mu)\left(\bar{x} \mid D_{t}\right) \underline{n}\right]
\end{aligned}
$$

$\mu\left(\bar{x} \mid D_{t}\right)$ is the posterior belief of the analysts that the reported earnings $D_{t}$ are based on the "true" earnings $\bar{x}$ as defined in equation (6).

Analysts aiming to provide accurate forecasts are therefore most concerned with estimating the manipulated part of earnings $\bar{n}$ and $\underline{n}$. In period $t$, the analysts do not have any other information besides the probability distribution of "true" earnings. The best analysts' forecast in this period is therefore the mean of "true" earnings plus the expected manipulation where the expectations are based on the probability distribution of the "true" earnings. In period $t+1$ the analysts are able to update their beliefs regarding the manipulation done in the previous period. In this period, their best forecast is therefore the mean of "true" earnings minus the expected manipulation based on the posterior beliefs of the analysts formed after observing the earnings reported in the period before. Formally, the analysts' best response is:

$$
\begin{aligned}
F_{t}^{*} & =p \bar{D}_{t}+(1-p) \underline{D}_{t} \\
& =p \bar{x}+(1-p) \underline{x}+p \bar{n}+(1-p) \underline{n}
\end{aligned}
$$


and

$$
\begin{aligned}
F_{t+1}^{*} & =p \bar{D}_{t+1}+(1-p) \underline{D}_{t+1} \\
& =p \bar{x}+(1-p) \underline{x}-\left[\mu\left(\bar{x} \mid D_{t}\right) \bar{n}+(1-\mu)\left(\bar{x} \mid D_{t}\right) \underline{n}\right]
\end{aligned}
$$

The investors in our model do not behave strategically. They adopt the expectations of the analysts and determine the price of firm's shares. At the end of period $t$ investors observe the earnings reported by the manager, compare them with the analysts' forecasts and build expectations regarding the future reported earnings, which are assumed to be equivalent to the expectations of the analysts. Thus, in dependence on the "true" earnings realization in period $t$, the prices of companies' share in period $t$ and $t+1$ are either

$$
\bar{P}_{t}=\bar{D}_{t}+\delta \bar{F}_{t+1}+v\left(\bar{D}_{t}-F_{t}\right)
$$

and

$$
\bar{P}_{t+1}=D_{t+1}+v\left(D_{t+1}-\bar{F}_{t+1}\right)
$$

or

$$
\underline{P}_{t}=\underline{D}_{t}+\delta \underline{F}_{t+1}+v\left(\underline{D}_{t}-F_{t}\right)
$$

and

$$
\underline{P}_{t+1}=D_{t+1}+v\left(D_{t+1}-\underline{F}_{t+1}\right)
$$

The strategy space of the manager is defined over the manipulated part of the reported earnings in each state of "true" earnings that realizes in period $t$, i.e. $S^{M}=(\bar{m}, \underline{m}) \in\left[m_{\min }, m_{\max }\right]$. This manipulation determined the level of reported earnings in period $t$ and $t+1$ since the "true" earnings are predefined and constant over time.

The manager's payoff is defined in (4). More specifically, manager's payoff is $U^{M}=\left(\bar{U}^{M}(),. \underline{U}^{M}().\right)$ in dependence on the "true" earnings realization in period $t$, where

$$
\bar{U}^{M}\left(D_{t}, F_{t}, F_{t+1}\right)=(1-\theta) \bar{P}_{t}\left(\bar{D}_{t}, \bar{F}_{t+1}, F_{t}\right)+\theta \delta \mathbb{E}_{t}^{M} \bar{P}_{t+1}\left(D_{t+1}, \bar{F}_{t+1}\right)
$$

respectively

$$
\underline{U}^{M}\left(D_{t}, F_{t}, F_{t+1}\right)=(1-\theta) \underline{P}_{t}\left(\underline{D}_{t}, \underline{F}_{t+1}, F_{t}\right)+\theta \delta \mathbb{E}_{t}^{M} \underline{P}_{t+1}\left(D_{t+1}, \underline{F}_{t+1}\right)
$$

with price functions $P_{t}=\left(\bar{P}_{t}, \underline{P}_{t}\right)$ and $P_{t+1}=\left(\bar{P}_{t+1}, \underline{P}_{t+1}\right)$ as defined in (10), (11), (12) and (13).

Using the players' strategy spaces and payoffs listed above, we define two equilibriums. In the first equilibrium, each player takes the action of the other players as given and chooses the strategy that maximizes the payoff. This is summarized in the following definition.

Definition 1 (Equilibrium). The strategy profile $\left(m^{*}, n^{*}, F_{t}^{*}, F_{t+1}^{*}, P_{t}^{*}, P_{t+1}^{*}\right)$ with $m^{*}=\left(\bar{m}^{*}, \underline{m}^{*}\right), n^{*}=\left(\bar{n}^{*}, \underline{n}^{*}\right), F_{t+1}^{*}=\left(\bar{F}_{t+1}^{*}, \underline{F}_{t+1}^{*}\right), P_{t}^{*}=\left(\bar{P}_{t}^{*}, \underline{P}_{t}^{*}\right)$ and $P_{t+1}^{*}=\left(\bar{P}_{t+1}^{*}, \underline{P}_{t+1}^{*}\right)$ together with the posterior beliefs $\mu$ of the analysts about the state of "true" earnings in period $t$ is a Bayesian Nash equilibrium (in pure strategies) if:

1. $\mu$ is determined by Bayes rule as in (6) whenever $D_{t}=(\bar{x}+\bar{m}, \underline{x}+\underline{m})$, 
2. $\bar{P}_{t}^{*}=\bar{D}_{t}^{*}+\delta \bar{F}_{t+1}^{*}+v\left(\bar{D}_{t}^{*}-F_{t}^{*}\right)$

$\bar{P}_{t+1}^{*}=D_{t+1}^{*}+v\left(D_{t+1}^{*}-\bar{F}_{t+1}^{*}\right)$

$\underline{P}_{t}^{*}=\underline{D}_{t}^{*}+\delta \underline{F}_{t+1}^{*}+v\left(\underline{D}_{t}^{*}-F_{t}^{*}\right)$

$\underline{P}_{t+1}^{*}=D_{t+1}^{*}+v\left(D_{t+1}^{*}-\underline{F}_{t+1}^{*}\right)$

3. For all $F_{t}, F_{t+1} \in S^{A}$

$$
U^{A}\left(F_{t}^{*}, F_{t+1}^{*} ; D_{t}^{*}, D_{t+1}^{*}\right) \geq U^{A}\left(F_{t}, F_{t+1} ; D_{t}^{*}, D_{t+1}^{*}\right)
$$

where the function $U^{A}($.$) is defined as in (7)$

4. For all $m \in S^{M}$

$$
U^{M}\left(D_{t}^{*}, D_{t+1}^{*} ; F_{t}^{*}, F_{t+1}^{*}\right) \geq U^{M}\left(D_{t}, D_{t+1} ; F_{t}^{*}, F_{t+1}^{*}\right)
$$

where the function $U^{M}($.$) is defined as in (14) and in (15) and$

5. $\bar{m}^{*}=\bar{n}^{*}$ respectively $\underline{m}^{*}=\underline{n}^{*}$.

In the second equilibrium concept, we consider the possibility that the manager is allowed to talk to the analysts and communicate her view on the next period earnings that she is going to report. Such statements summarized in earnings estimates are known as earnings guidance. They are relevant for the manager's incentives to manipulate earnings for several reasons. First, earnings guidance influences the consensus forecast since analysts need to adjust their expectations according to the announced reporting strategy in order to minimize their mean forecasts errors, i.e. $\bar{n}=\bar{m}$ respectively $\underline{n}=\underline{m}$. Second, the manager providing earnings guidance would, in equilibrium, anticipate the analysts' reaction to her announcements and change her reporting (manipulation) strategy accordingly. If the manager guides the analysts, she solve a similar problem as the leader in Stackelberg's leader-follower game. The equilibrium in the setting with guidance is defined as follows.

Definition 2 (Equilibrium with Guidance). The strategy profile $\left(m^{*}, F_{t}^{*}, F_{t+1}^{*}, P_{t}^{*}, P_{t+1}^{*}\right)$ with $m^{*}=\left(\bar{m}^{*}, \underline{m}^{*}\right), F_{t+1}^{*}=\left(\bar{F}_{t+1}^{*}, \underline{F}_{t+1}^{*}\right), P_{t}^{*}=$ $\left(\bar{P}_{t}^{*}, \underline{P}_{t}^{*}\right)$ and $P_{t+1}^{*}=\left(\bar{P}_{t+1}^{*}, \underline{P}_{t+1}^{*}\right)$ together with the posterior beliefs $\mu$ of the analysts about the state of "true" earnings in period t is a Bayesian Nash equilibrium (in pure strategies) if:

1. $\mu$ is determined by Bayes rule as in (6) whenever $D_{t}=\{\bar{x}+\bar{m}, \underline{x}+\underline{m}\}$,

2. $\bar{P}_{t}^{*}=\bar{D}_{t}^{*}+\delta \bar{F}_{t+1}^{*}+v\left(\bar{D}_{t}^{*}-F_{t}^{*}\right)$

$\bar{P}_{t+1}^{*}=D_{t+1}^{*}+v\left(D_{t+1}^{*}-\bar{F}_{t+1}^{*}\right)$

$\underline{P}_{t}^{*}=\underline{D}_{t}^{*}+\delta \underline{F}_{t+1}^{*}+v\left(\underline{D}_{t}^{*}-F_{t}^{*}\right)$

$\underline{P}_{t+1}^{*}=D_{t+1}^{*}+v\left(D_{t+1}^{*}-\underline{F}_{t+1}^{*}\right)$

3. For all $m \in S^{M}$

$$
U^{M}\left(D_{t}^{*}, D_{t+1}^{*} ; \mathbb{E}^{A}\left(D_{t}^{*}\right), \mathbb{E}^{A}\left(D_{t+1}^{*}\right)\right) \geq U^{M}\left(D_{t}, D_{t+1} ; \mathbb{E}^{A}\left(D_{t}^{*}\right), \mathbb{E}^{A}\left(D_{t+1}^{*}\right)\right)
$$

where the function $U^{M}($.$) is defined as in (14) and in (15) and$

$\mathbb{E}^{A}\left(D_{t}^{*}\right)=p \bar{x}+(1-p) \underline{x}+p \bar{m}^{*}+(1-p) \underline{m}^{*}$

$\mathbb{E}^{A}\left(D_{t+1}^{*}\right)=p \bar{x}+(1-\bar{p}) \underline{x}-\left[\mu\left(\bar{x} \mid D_{t}^{*}\right) \bar{m}^{*}+(1-\mu)\left(\bar{x} \mid D_{t}^{*}\right) \underline{m}^{*}\right]$ 


\section{Players' Strategies in Equilibrium}

The following analysis aims to show how the manipulation decision of the manager depends on the market conditions, the manager's compensation package and the guidance provided by the manager to the firm's outsiders. The market conditions are defined with respect to the investors' attitude towards earnings reports that are above or below the analysts' consensus forecast. The compensation package of the manager may include either shares or stock options of the company. The manager may or may not provide guidance to the analysts.

When analyzing the relevance of the market conditions, we distinguish two cases. First, we consider a situation where the investors do not use the analysts' forecasts as a reference point when determining the price of firm's shares. We denote this situation by $\bar{B}$ for "non-behavioral". In this case, analysts' forecasts are not a target that the manager aim to meet when deciding to manipulate earnings since there is no premium the manager can get by reporting earnings at or above the consensus forecast. Nevertheless, analysts' expectations with respect to the manipulated part of earnings affect the price of the company shares since the investors are supposed to adapt them fully and adjust the price of the firm's shares accordingly. In this case, the analysts are only information providers. Second, we consider a situation where analysts are target setters and information providers at the same time. We denote this situation by $B$ for "behavioral". In this case, the analysts' reports and forecasts are used by investors not only to build expectations regarding the manipulated part of earnings but also to determine whether the price of the firm's shares should include a premium (or a discount) from meeting (falling short of) the consensus forecast.

The manipulation decision of the manager depends additionally on the manager's compensation package. We assume that the manager is compensated either with company shares $(S)$ or with stock options $(C)$, which can be sold respectively exercised in both periods. The percentage of shares respectively stock options hold by the manager reflects her time preferences, which are assumed to be private knowledge. If the manager holds stocks then her payoff is linked directly to the market price of firm's shares. In contrast, if the manager holds stock options with an exercise price equal to the expected value of "true" earnings, the payoff of the manager is affected only if the price of the firm's shares increases above the fundamental value of the firm, i.e. the expected value of "true" earnings.

The optimal reporting depends additionally on whether the manager does $(G)$ or does not guide $(\bar{G})$. The difference is in the manager's and analysts' attitude toward the actions of the other players. In particular, if the manager provides guidance, the analysts would follow it in order to minimize their mean squared forecast errors. The manager anticipates the reaction of the analysts' and adjust her manipulation strategy accordingly. If the manager does not provide any guidance, she cannot be sure how the analysts will respond to her reporting and choose the manipulation strategy that is best response to some forecast of the analysts.

In equilibrium, the manager's reporting can be either revealing $(R)$ or nonrevealing $(\bar{R})$. The reporting is revealing if the firm's outsiders are able to "read" behind the numbers and adjust their expectations in response to the manipulation decision of the manager. The reporting is non-revealing if the 
firm's outsiders cannot update their beliefs even if they act as rational Bayesians. In the non-revealing equilibrium, the firm's outsiders can be systematically fooled.

\subsection{Optimal Reporting of a Manager Playing with Behav- ioral and Non-Behavioral Investors}

Consider first the case where the manager holds shares $(S)$, do not guide $(\bar{G})$, and the investors do not consider the analysts' forecasts as a reference point when evaluating the earnings reported by the manager, i.e. the function $v($. does not affect the manager's payoff, or $(\bar{B})$. In this case, the manager does not have incentives to meet the analysts forecasts so that her manipulation decision is driven only by her time preferences $\theta$ and the time value of money $\delta$. The following theorem proves this.

Theorem 1 ( $S \overline{B G} R$ reporting). If $\theta \in\left[0 ; \frac{1}{1+\delta}\right)$, we obtain the following revealing equilibrium:

$\bar{m}^{*}=\underline{m}^{*}=\bar{n}^{*}=\underline{n}^{*}=m_{\max }$,

$F_{t}^{*}=p \bar{x}+(1-p) \underline{x}+m_{\max }$

$\bar{F}_{t+1}^{*}=\underline{F}_{t+1}^{*}=p \bar{x}+(1-p) \underline{x}-m_{\max }$,

$\bar{P}_{t}^{*}=\bar{x}+m_{\max }+\delta\left(p \bar{x}+(1-p) \underline{x}-m_{\max }\right)$,

$\underline{P}_{t}^{*}=\underline{x}+m_{\max }+\delta\left(p \bar{x}+(1-p) \underline{x}-m_{\max }\right)$,

$\bar{P}_{t+1}^{*}=\bar{x}-m_{\max }$,

$\underline{P}_{t+1}^{*}=\underline{x}-m_{\max }$

and the posterior beliefs of the analysts $\mu \in[0,1]$ is a revealing Bayesian Nash equilibrium (in pure strategies).

If $\theta=\frac{1}{1+\delta}$, we obtain the following revealing equilibrium:

$\bar{m}^{*}=m=\bar{n}^{*}=n^{*}=0$,

$F_{t}^{*}=\bar{F}_{t+1}^{*}=\underline{F}_{t+1}^{*}=p \bar{x}+(1-p) \underline{x}$,

$\bar{P}_{t}^{*}=\bar{x}+\delta(p \bar{x}+(1-p) \underline{x})$,

$\underline{P}_{t}^{*}=\underline{x}+\delta(p \bar{x}+(1-p) \underline{x})$,

$\bar{P}_{t+1}^{*}=\bar{x}$

$\underline{P}_{t+1}^{*}=\underline{x}$

and the posterior beliefs of the analysts $\mu \in[0,1]$ is a revealing Bayesian Nash equilibrium (in pure strategies).

If $\theta \in\left(\frac{1}{1+\delta}, 1\right]$, we obtain the following revealing equilibrium

$\bar{m}^{*}=\underline{m}=\bar{n}^{*}=\underline{n}^{*}=m_{\text {min }}$,

$F_{t}^{*}=p \bar{x}+(1-p) \underline{x}+m_{\text {min }}$

$\bar{F}_{t+1}^{*}=\underline{F}_{t+1}^{*}=p \bar{x}+(1-p) \underline{x}-m_{\text {min }}$,

$\bar{P}_{t}^{*}=\bar{x}+m_{\text {min }}+\delta\left(p \bar{x}+(1-p) \underline{x}-m_{\text {min }}\right)$,

$\underline{P}_{t}^{*}=\underline{x}+m_{\min }+\delta\left(p \bar{x}+(1-p) \underline{x}-m_{\min }\right)$,

$\bar{P}_{t+1}^{*}=\bar{x}-m_{m i n}$,

$\underline{P}_{t+1}^{*}=\underline{x}-m_{\min }$

and the posterior beliefs of the analysts $\mu \in[0,1]$ is a revealing Bayesian equilibrium (in pure strategies).

The intuition is the following. If investors do not consider the analysts' forecasts as a reference point, the price of firm's shares depends only on the present value of the reported earnings, i.e. there is no premium (discount) for meeting (falling short of) the analysts' expectations. Thus, the manipulation decision 
of the manager can be considered as a pure income shift over time depending on the time preferences of the manager $\theta$ and the time value of money $\delta$ but not on the investors' preferences $\beta$ with respect to earnings reports above or below the consensus forecast. The more shares the manager aims to sell in the current (following) period, the stronger is her incentive to manipulate earnings up (down) since the manipulation increases the price of the shares that the manager is willing to sell in that period. In equilibrium, the manager prefers to manipulate earnings in order to shift income according to her time preferences although the analysts see this, adjust their expectations and influence the present value of the firm's earnings. The only case where the manager does not have any incentives to manipulate earnings is when money does not have any time value. This is the case where $\delta=1$ and the manager is indifferent between holding shares in period $t$ or in period $t+1$, i.e. $\theta=\frac{1}{2}$.

To see how the manager's incentives to manipulate earnings change with the market conditions, in the following we consider a situation where the investors require a discount for holding the shares of firms reporting earnings below the analysts' expectations, i.e. if $v() \neq$.0 respectively if $\beta>1$. In this case, the manager has strong incentives to manipulate the earnings even if she is indifferent between holding shares over both periods. In fact, it is this indifference that motivates the manager to manipulate earnings as proved in the following theorem.

Theorem 2 ( $S B \overline{G R}$ reporting). If $\frac{2}{2+\delta(1+p)+\delta \beta(1-p)}<\theta<\frac{1}{1+\delta}$ and $p>\frac{1}{2}$ we obtain the following non-revealing equilibrium:

$\bar{m}^{*}=(1-p)(\underline{x}-\bar{x})$,

$\underline{m}^{*}=p(\bar{x}-\underline{x})$,

$F_{t}^{*}=\bar{F}_{t+1}^{*}=\underline{F}_{t+1}^{*}=p \bar{x}+(1-p) \underline{x}$,

$\bar{P}_{t}^{*}=\bar{x}+(1-p)(\underline{x}-\bar{x})+\delta(p \bar{x}+(1-p) \underline{x})+v(\bar{x}+(1-p)(\underline{x}-\bar{x})-p \bar{x}-(1-p) \underline{x})$,

$\underline{P}_{t}^{*}=\underline{x}+p(\bar{x}-\underline{x})+\delta(p \bar{x}+(1-p) \underline{x})+v(\underline{x}+p(\bar{x}-\underline{x})-p \bar{x}-(1-p) \underline{x})$,

$\bar{P}_{t+1}^{*}=\bar{x}-(1-p)(\underline{x}-\bar{x})+v(\bar{x}-(1-p)(\underline{x}-\bar{x})-p \bar{x}-(1-p) \underline{x})$,

$\bar{P}_{t+1}^{*}=\underline{x}-(1-p)(\underline{x}-\bar{x})+v(\underline{x}-(1-p)(\underline{x}-\bar{x})-p \bar{x}-(1-p) \underline{x})$

$\underline{P}_{t+1}^{*}=\bar{x}-p(\underline{x}-\bar{x})+v(\bar{x}-p(\underline{x}-\bar{x})-p \bar{x}-(1-p) \underline{x})$,

$\underline{P}_{t+1}^{*}=\underline{x}-p(\underline{x}-\bar{x})+v(\underline{x}-p(\underline{x}-\bar{x})-p \bar{x}-(1-p) \underline{x})$

and the posterior beliefs of the analysts $\mu=p$ is a non-revealing Bayesian equilibrium (in pure strategies).

The intuition for the existence of this equilibrium is the following. Given that the "true" earnings are above the consensus forecast, which is equal to the expected "true" earnings in this equilibrium, the manager deciding not to manipulate earnings reports a positive surprise in the current period and a positive or a negative surprise in the period ahead. If, however, the manager sells shares in both periods, she has incentives to "save" the earnings in the current period reporting what the analysts expect and use the "savings" to cover losses that might occur in the next period, when the "true" earnings are below the consensus forecast. This is a better strategy for the manager since reporting earnings below the consensus forecast is associated with a price decline that cannot be compensated with a price increase following a positive earnings surprise in the current period given that $\beta>1$.

Similarly, if the "true" earnings in the current period are below the consensus forecast, the manager selling shares in both periods is better off if she "borrow" 
earnings from the next period than to report a loss by reporting truthfully for example. This is because the price decline due to the negative surprise in the current period is stronger than the price increase in the future when the "true" earnings are above the consensus forecast given that $\beta>1$. Thus, because of the asymmetric price reaction to earnings surprises reflected in the loss aversion parameter $\beta>1$, the expected payoff of the manager is higher if she "borrows" earnings from the future to prevent reporting negative earnings surprises in the current period and "saves" earnings in the current period in order to prevent reporting negative surprises in the future.

Note that this equilibrium exists only if $\beta>1$. In other words, only if there is a premium (discount) for meeting (falling short of) the analysts' expectations, the manager has incentives to manipulate earnings in order to meet the analysts' forecasts so that in equilibrium her manipulation cannot be detected by the firm's outsiders. If $\beta=1$, there is no manager who prefers to play this equilibrium.

Overall, the higher the investors' loss aversion, the higher is the manager's incentives to choose this equilibrium. This is reflected in the restrictions for the manager's time preferences $\theta$. The higher the parameter $\beta$ reflecting investors' loss aversion, the lower is the lower bound of the parameter $\theta$ defining which managers would choose to play this equilibrium. Outside the defined range the managers prefer to follow a different strategy.

In the following we consider the extreme cases, where the manager can either "save" earnings for the future and take the "big bath", i.e. $\bar{m}=\underline{m}=m_{m i n}$, or "borrow" earnings from the future, i.e. $\bar{m}=\underline{m}=m_{\max }$. If the manager decides to follow one of these strategies, her reporting would be revealing since $\bar{D}_{t} \neq \underline{D}_{t}$ in the sense that the analysts would be able to detect the manipulation and adjust their beliefs accordingly.

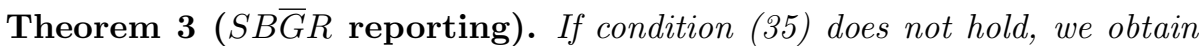
the following revealing equilibria:

For $\theta \in\left[0, \frac{2}{2+\delta(1+p)+\delta \beta(1-p)}\right)$

$\bar{m}^{*}=\underline{m}=m_{\max }$,

$F_{t}^{*}=p \bar{x}+(1-p) \underline{x}+m_{\max }$,

$\bar{F}_{t+1}^{*}=\underline{F}_{t+1}^{*}=p \bar{x}+(1-p) \underline{x}-m_{\max }$,

$\bar{P}_{t}^{*}=\bar{x}+m_{\max }+\delta\left(p \bar{x}+(1-p) \underline{x}-m_{\max }\right)+v(\bar{x}-p \bar{x}-(1-p) \underline{x})$,

$\underline{\underline{P}}_{t}^{*}=\underline{x}+m_{\max }+\delta\left(p \bar{x}+(1-p) \underline{x}-m_{\max }\right)+v(\underline{x}-p \bar{x}-(1-p) \underline{x})$,

$\bar{P}_{t+1}^{*}=\bar{x}-m_{\max }+v(\bar{x}-p \bar{x}+(1-p) \underline{x})$,

$\underline{P}_{t+1}^{*}=\underline{x}-m_{\max }+v(\underline{x}-p \bar{x}+(1-p) \underline{x})$

and the posterior beliefs of the analysts $\mu \in[0,1]$ is a revealing Bayesian equilibrium (in pure strategies).

For $\theta \in\left(\frac{(1+\beta)}{(1+\beta)(1+\delta)+\delta p(1-\beta)}, 1\right]$

$\bar{m}^{*}=\underline{m}=m_{\min }$

$F_{t}^{*}=\overline{p \bar{x}}+(1-p) \underline{x}+m_{\text {min }}$,

$\bar{F}_{t+1}^{*}=\underline{F}_{t+1}^{*}=p \bar{x}+(1-p) \underline{x}-m_{m i n}$,

$\bar{P}_{t}^{*}=\bar{x}+m_{\text {min }}+\delta\left(p \bar{x}+(1-p) \underline{x}-m_{\text {min }}\right)+v(\bar{x}-p \bar{x}-(1-p) \underline{x})$,

$\underline{P}_{t}^{*}=\underline{x}+m_{\text {min }}+\delta\left(p \bar{x}+(1-p) \underline{x}-m_{\text {min }}\right)+v(\underline{x}-p \bar{x}-(1-p) \underline{x})$,

$\bar{P}_{t+1}^{*}=\bar{x}-m_{\text {min }}+v(\bar{x}-p \bar{x}+(1-p) \underline{x})$,

$\underline{P}_{t+1}^{*}=\underline{x}-m_{\min }+v(\underline{x}-p \bar{x}+(1-p) \underline{x})$

and the posterior beliefs of the analysts $\mu \in[0,1]$ is a revealing Bayesian equi- 
librium (in pure strategies).

The results in the last two theorems show that the optimal reporting strategy of the manager depends strongly on her time preferences $\theta$ as a function of the time value of money $\delta$, the distribution of true earnings $p$ and the loss aversion of the investors $\beta$. If the manager is interested in selling shares in the current and in the following period, she has incentives to meet the analysts' forecasts in the current period as proved in the non-revealing equilibrium in Theorem 2. However, if the manager desires to sell more shares in the current period for example, she would "borrow" earnings from the future independently on the state of "true" earnings. In equilibrium, the analysts would adjust their consensus forecasts up by the amount of the revenues the manager is able to shift over time, i.e. $m_{\max }$. This action of the analysts eliminates the price impact of the manipulation but the manager would still do it. This is because any other strategy is associated with a lower payoff for the manager given the forecasts of the analysts and the time preferences of the manager to sell more shares in the current period, so that in equilibrium the manager manipulates the earnings up as expected by the analysts.

The same intuition applies in the case where the manager is more interested in selling shares in period $t+1$. In this case, the manager would "save" earnings in the current period, i.e. take the "big bath" in order to increase the price of the firm in the period when she plan to sell her shares. Again, in equilibrium the analysts expect this and adjust their forecasts so that the manager does not get any premium for manipulating the earnings. Nevertheless, the manager would not deviate from this strategy since any other strategy is associated with a lower payoff given her time preferences and the forecasts of the analysts.

To derive more general conclusions on the importance of the market conditions for the manager's incentives to manipulate earnings, assume that there are many managers with equally distributed time preferences $\theta$. Then, we can conclude based on the previous analysis that the absolute level of manipulation in the economy is lower if the investors consider the analysts' forecasts as a reference point. This results follows from the fact that in equilibrium where $\beta>1$ there are some managers playing the non-revealing equilibrium $(S B \overline{G R})$, where the absolute level of manipulation is per definition lower compared to the upper and lower bounds of manipulation, chosen by the managers in the revealing equilibrium where there is no premium (discount) for meeting (falling short of) the investors' expectations $(S \overline{B G} R)$. This is illustrated graphically in Figure 1. 
Figure 1: Optimal Manipulation Strategies of Managers Holding Shares and Playing with Behavioral and Non-Behavioral Investors

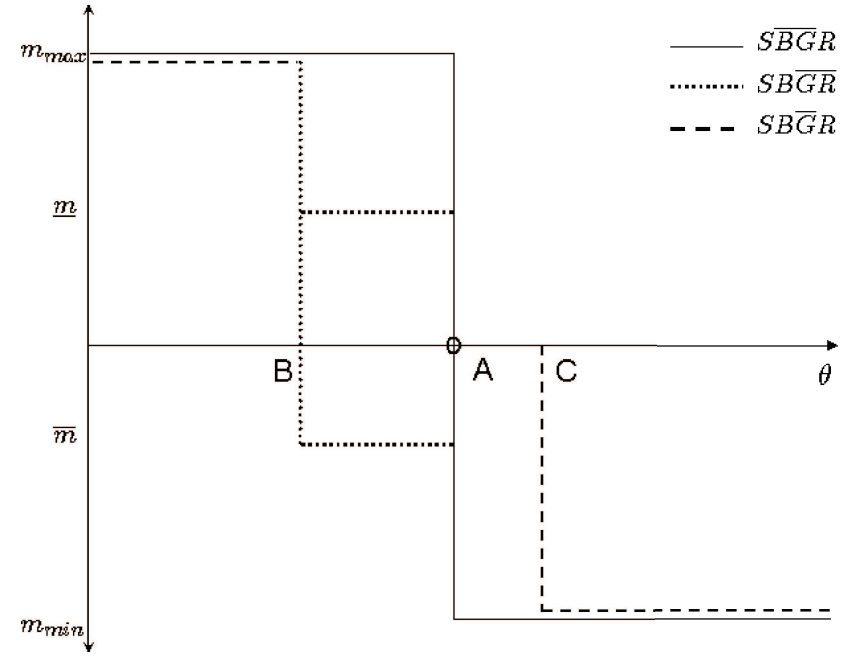

The figure summarizes the optimal manipulation strategies of a manager holding shares $(S)$, providing no guidance $(\bar{G})$ under different market conditions ( $B$ and $\bar{B}$ ) in dependence on her time preferences $\theta$. The points $A=\frac{1}{1+\delta}, B=$ $\frac{2}{2+\delta(1+p)+\delta \beta(1-p)}$, and $C=\frac{1+\beta}{(1+\beta)(1+\delta)+\delta p(1-\beta)}$ represent bounds for the time preferences $\theta$ for which the manipulation strategies are part of a revealing $(R)$ or non-revealing $(\bar{R})$ equilibrium proved in Theorem 1, 2 and 3 .

\subsection{Optimal Reporting of a Manager Holding Stock Op- tions}

If the manager's compensation package includes stock options instead of shares her optimal reporting strategy changes since the manager's payoff becomes a non-linear function of the price of firm's shares. To analyze the manager's incentive to manipulate earnings, we define $\theta$ is the percentage of stock options that the manager desires to carry over to period $t+1$. Hence, $1-\theta$ is the percentage of options that the manager is allowed to exercise in period $t$.

Let $C_{t}$ be the market value of a stock option with a strike equal to the mean "true" earnings, $p \bar{x}+(1-p) \underline{x}$, which is denoted by $X$. In particular,

$$
\begin{gathered}
\bar{C}_{t}=\max \left(\bar{P}_{t}-X, 0\right) \quad \underline{C}_{t}=\max \left(\underline{P}_{t}-X, 0\right) \\
\bar{C}_{t+1}=\max \left(\bar{P}_{t+1}-X, 0\right) \quad \underline{C}_{t+1}=\max \left(\underline{P}_{t+1}-X, 0\right)
\end{gathered}
$$

where $\bar{P}_{t}$ and $\underline{P}_{t}$ are determined by (10) respectively (12) and $\bar{P}_{t+1}$ and $\underline{P}_{t+1}$ are determined by (11) respectively (13).

Again, in dependence on whether the analysts are in their role as target setters or not, we distinguish two (revealing) equilibria. The first one summarizes the players' strategies in equilibrium when the analysts are only information providers i.e. if investors do not pay a premium (or require a discount) for meeting (falling short of) the consensus forecast, i.e. $v()=$.0 . The second one summarizes the players' strategies in equilibrium when the analysts are also target setters, i.e. $v() \neq$.0 . 
Theorem 4 ( $C \overline{B G} R$ reporting). If the manager holds stock options and $v()=$.0 we obtain the following equilibrium

For $\theta \in\left(\frac{2}{2+\delta} ; 1\right]$

$\bar{m}^{*}=\underline{m}^{*}=m_{\min }$

$F_{t}^{*}=\bar{p} \bar{x}+(1-p) \underline{x}+m_{\text {min }}$

$\bar{F}_{t+1}^{*}=\underline{F}_{t+1}^{*}=p \bar{x}+(1-p) \underline{x}-m_{\min }$

$\bar{C}_{t}^{*}=\underline{C}_{t}^{*}=0$

$\bar{C}_{t+1}^{*}=\bar{x}-m_{\min }-X$

$\underline{C}_{t+1}^{*}=\underline{x}-m_{\text {min }}-X$

and the posterior beliefs of the analysts $\mu \in[0,1]$ is a revealing Bayesian equilibrium (in pure strategies).

For $\theta \in\left[0, \frac{2(1-p)+\delta(2 p-3)}{2(1-p)+\delta(2 p-1)}\right)$ and $\delta<\frac{2(1-p)}{3-2 p}$

$\bar{m}^{*}=\underline{m}^{*}=m_{\max }$

$F_{t}^{*}=p \bar{x}+(1-p) \underline{x}+m_{\max }$

$\bar{F}_{t+1}^{*}=\underline{F}_{t+1}^{*}=p \bar{x}+(1-p) \underline{x}-m_{\max }$

$\bar{C}_{t}^{*}=\bar{x}+m_{\max }+\delta\left(p \bar{x}+(1-p) \underline{x}-m_{\max }\right)-X$

$\underline{C}_{t}^{*}=\underline{x}+m_{\max }+\delta\left(p \bar{x}+(1-p) \underline{x}-m_{\max }\right)-X$

$\overline{\bar{C}}_{t+1}^{*}=0$

$\underline{C}_{t+1}^{*}=0$

and the posterior beliefs of the analysts $\mu \in[0,1]$ is a revealing Bayesian equilibrium (in pure strategies).

To get an intuition on this result particularly in the context of the previous, recall that the manager's best strategy is to report truthfully if she holds shares, the time value of money is equal to zero and the manager is indifferent between selling shares in period $t$ or in period $t+1$ (see Theorem 1). Such indifference cannot make the no-manipulation strategy attractive for the manager holding stock options because her options become worthless if the next period "true" earnings are low and there is no earnings manipulation pushing the price up. Hence, if the manager is compensated with stock options, she will never prefer to report truthfully in equilibrium.

Comparing the optimal manipulation strategies of the manager in dependence on her compensation package, we can also conclude that there will be less manipulation in absolute terms in the economy if the managers in the economy are compensated with options instead of shares. The reason for this is that options may become worthless whereas the stock price may fall below the fundamentals but it cannot become negative. Thus, the revealing manipulation strategies $\bar{m}=\underline{m}=m_{\min }$ and $\bar{m}=\underline{m}=m_{\max }$ are attractive only for the manager with time preferences $\theta$ that are shifted toward the period where the payoff is positive. More precisely, if the manager's payoff is positive in period $t+1$ but equal to zero in period $t$, the manager would prefer to sell in period $t+1$. Such preferences are reflected in a higher restriction on the parameter $\theta$ for a given manipulation strategy to be optimal. For example, if we compare the restriction on $\theta$ for the equilibrium strategy $\bar{m}=\underline{m}=m_{m i n}$, we can see that the manager holding shares follows this strategy if her time preference parameter $\theta$ is lower than the time preference parameter $\theta$ of the manager holding stock options, i.e. $\frac{1}{1+\delta}<\frac{2}{2+\delta}$ (see Theorem 1 and 4 ). This means that the latter follows the manipulation strategy $m_{m i n}$ if she prefers to exercise her options in period $t+1$ instead of period $t$ which is consistent with the observation that with the 
strategy $m_{\min }, \bar{C}_{t}=\underline{C}_{t}=0$ but $\bar{P}_{t}>0$ and $\underline{P}_{t}>0$. In other words, because the manager holding stock options carries the risk to get nothing for her stock options in the current period, she would follow the strategy $\bar{m}=\underline{m}=m_{\text {min }}$ only if her time preferences are such that she can exercise more options in $t+1$ with $\bar{C}_{t+1}>0$ and $\underline{C}_{t+1}>0$ than in $t$ with $\bar{C}_{t}=\underline{C}_{t}=0$ compared to the manager holding shares where $P_{t}>0$ and $P_{t+1}>0$.

Similar considerations apply when we compare the manager's incentives to manipulate earnings in dependence on her compensation package for the case where the manager chooses to play $\bar{m}=\underline{m}=m_{\max }$. Since with this strategy $\bar{C}_{t+1}=\underline{C}_{t+1}=0$ but $\bar{P}_{t+1}>0$ and $\underline{P}_{t+1}>0$, the manager holding stock options would follow the strategy only if she has stronger incentives to exercise them in the current period compared to the manager holding stocks. In particular, the strategy is optimal for a manager holding options if she has a lower $\theta$ than a manager holding shares, i.e. $\frac{2(1-p)+\delta(2 p-3)}{2(1-p)+\delta(2 p-1)}<\frac{1}{1+\delta}$ (see Theorem 1 and 4). This is equivalent to the conclusion that the absolute level of manipulation in the economy is lower if the managers in that economy are compensated with options instead of shares.

Having derived conclusions on the implications of the manager's compensation on her manipulation strategies in equilibrium, we continue the analysis by considering the impact of the market conditions in the case that manager is compensated with stock options. In particular, we are interested how the optimal manipulation strategy of the manager holding stock options changes if investors are behavioral, i.e. if they use the analysts' forecasts as a reference point when evaluating earnings reports. In the previous analysis focusing on a manager holding shares we have shown that a manager interested to sell shares in both periods prefers to manipulate the earnings in order to meet the analysts' forecasts. In the following, we analyze the existence of this non-revealing equilibrium for the case that the manager holds stock options.

Theorem 5 ( $C B \bar{G} R$ reporting). If the manager holds stock options and $\theta \in\left[\frac{4}{4+3 \delta p-2 \delta p^{2}}, 1\right]$ then

$\bar{m}^{*}=\underline{m}^{*}=m_{\min }$

$F_{t}=p \bar{x}+(1-p) \underline{x}+m_{m i n}$,

$\bar{F}_{t+1}^{*}=\underline{F}_{t+1}^{*}=p \bar{x}+(1-p) \underline{x}-m_{m i n}$,

$\bar{C}_{t}^{*}=\bar{x}+m_{\min }+\delta\left(p \bar{x}+(1-p) \underline{x}-m_{\min }\right)+\bar{x}-p \bar{x}-(1-p) \underline{x}-X$,

$\underline{C}_{t}^{*}=0$,

$\overline{\bar{C}}_{t+1}=\bar{x}-m_{\min } \bar{x}-p \bar{x}-(1-p) \underline{x}-X$,

$\underline{C}_{t+1}=0$

and the posterior beliefs of the analysts $\mu \in[0,1]$ is a revealing Bayesian equilibrium (in pure strategies).

If investors are behavioral and the manager holds stock options instead of shares then the no-manipulation strategy and the strategy of manipulating earnings in order to meet the analysts' forecasts are dominated strategies from the manager's point of view. Thus, in equilibrium the manager's manipulation strategy is revealing.

To compare the absolute levels of manipulation in the economy with behavioral and non-behavioral investors, we assume that $\delta>\frac{2 p-2}{2 p-3}$ so that the strategy $\bar{m}=\underline{m}=m_{\max }$ is not an equilibrium strategy for the manager holding 
shares and playing with non-behavioral investors (see Theorem 4 ). ${ }^{2}$ Since the restriction on $\theta$ for the strategy $\bar{m}=\underline{m}=m_{\min }$ to be optimal for the manager playing with non-behavioral investors, i.e. $\theta>\frac{2}{2+\delta}$ (see Theorem 4 ), is lower than the restriction on $\theta$ for the manager playing with behavioral investors, i.e. $\theta>\frac{4}{4+3 \delta p-2 \delta p}$ (see Theorem 5) for all $0<\delta \leq 1$ and $0 \leq p \leq 1$, we may conclude that there will be less manipulation in the economy in absolute terms if the managers in that economy holding stock options play with behavioral than with non-behavioral investors (see Figure 2). In other words, the fact that the managers holding stock options play the earnings game with investors considering the analysts' forecasts as a reference point does not increase the absolute level of manipulation in the economy compared to the case with non-behavioral investors.

Figure 2: Optimal Manipulation Strategies of a Manager Holding Stock Options and Playing with Behavioral and Non-Behavioral Investors

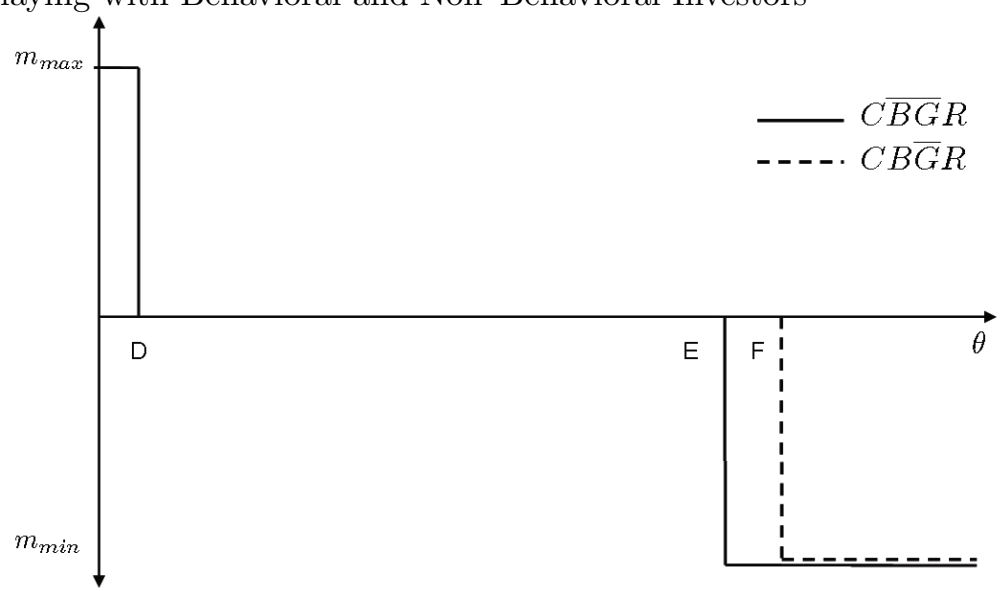

The figure summarizes the optimal manipulation strategies of a manager holding stock options $(C)$, providing no guidance $(\bar{G})$ under different market conditions $(B$ and $\bar{B})$ in dependence on her time preferences $\theta$. The points $D=\frac{2(1-p)+\delta(2 p-3)}{2(1-p)+\delta(2 p-1)}, E=\frac{2}{2+\delta}$, and $F=\frac{4}{4+3 \delta p-2 \delta p^{2}}$ represent bounds for the time preferences $\theta$ for which the manipulation strategies are part of the revealing $(\bar{R})$ equilibria proved in Theorem 4 and 5 .

\subsection{Optimal Reporting of a Manager Guiding Analysts}

Having analyzed the earnings game with a manager endowed with discretion to manipulate the reported earnings numbers in dependence on the market conditions and her compensation package, in this section we focus on the earnings game with a manager providing earnings guidance to analysts. Studying the manager's incentives to manipulate earnings, we aim to answer the question whether the absolute level of earnings manipulation increase when managers provide guidance compared to the no-guidance case.

${ }^{2}$ This is a realistic assumption, since in the extreme case where $p=0$ the requirement is that $\delta>2 / 3$ which correspond to a maximum interest rate of $50 \%$. The higher the probability $p$ the less binding is the restriction on $\delta$. 
To answer this question we consider first an economy with non-behavioral investors and a manager holding shares. If the manager provides earnings guidance, she indirectly announce how she is planning to shift earnings over time. Analysts aiming to minimize the mean squared forecast errors would adjust their estimates according to the provided guidance. The manager considers the best response of the analysts, i.e. how they will respond to the announced guidance, and then she picks a manipulation strategy that is a best response to the predicted response of the analysts. In equilibrium, the analysts adjust their forecasts with the expected manipulation as a response.

The following theorem formalizes the guidance effect on the manipulation decision of the manager holding shares under the assumption that investors do not use the analysts' forecasts as a reference point, i.e. $v()=$.0 .

Theorem 6 ( $S \bar{B} G R$ reporting). If the manager guides the analysts and $v()=$. 0 , we obtain the following equilibria:

For $\theta \in[0 ; 1-\delta]$,

$\bar{m}^{*}=\underline{m}=m_{\max }$,

$F_{t}^{*}=\bar{F}_{t+1}^{*}=\underline{F}_{t+1}^{*}=p \bar{x}+(1-p) \underline{x}-m_{\max }$,

$\bar{P}_{t}^{*}=\bar{x}+m_{\max }+\delta\left(p \bar{x}+(1-p) \underline{x}-m_{\max }\right)$,

${\underline{P_{t}^{*}}}^{*}=\underline{x}+m_{\max }+\delta\left(p \bar{x}+(1-p) \underline{x}-m_{\max }\right)$,

$\bar{P}_{t+1}^{*}=\bar{x}-m_{\max }$

$\underline{P}_{t+1}^{*}=\underline{x}-m_{\max }$

and the posterior beliefs of the analysts $\mu \in[0,1]$ is a Bayesian Nash equilibrium

(in pure strategies).

For $\theta=\frac{1}{1+\delta}$,

$\bar{m}^{*}=m=0$,

$F_{t}^{*}=\bar{F}_{t+1}^{*}=\underline{F}_{t+1}^{*}=p \bar{x}+(1-p) \underline{x}$,

$\bar{P}_{t}^{*}=\bar{x}+\delta(p \bar{x}+(1-p) \underline{x})$,

$\underline{P}_{t}^{*}=\underline{x}+\delta(p \bar{x}+(1-p) \underline{x})$,

$\bar{P}_{t+1}^{*}=\bar{x}$,

$\underline{P}_{t+1}^{*}=\underline{x}$

and the posterior beliefs of the analysts $\mu \in[0,1]$ is a Bayesian Nash equilibrium (in pure strategies).

For $\theta \in(1-\delta, 1] \backslash \frac{1}{1+\delta}$,

$\bar{m}^{*}=\underline{m}=m_{\text {min }}$,

$F_{t}^{*}=p \bar{x}+(1-p) \underline{x}+m_{m i n}$,

$\bar{F}_{t+1}^{*}=\underline{F}_{t+1}^{*}=p \bar{x}+(1-p) \underline{x}-m_{\min }$

$\bar{P}_{t}^{*}=\bar{x}+m_{\text {min }}+\delta\left(p \bar{x}+(1-p) \underline{x}-m_{\text {min }}\right)$,

$\underline{P}_{t}^{*}=\underline{x}+m_{\min }+\delta\left(p \bar{x}+(1-p) \underline{x}-m_{\min }\right)$,
$\bar{P}_{t+1}^{*}=\bar{x}-m_{\min }$,

$\underline{P}_{t+1}^{*}=\underline{x}-m_{\min }$

and the posterior beliefs of the analysts $\mu \in[0,1]$ is a Bayesian Nash equilibrium (in pure strategies).

If the manager guides the analysts she has incentives to "save" earnings for the future, unless $\theta<1-\delta$. This is because any earnings manipulation in the current period is almost "undone" by the analysts, so that the only price impact the manager is able to achieve with the earnings manipulation is in period $t+1$, when the game ends. If $\delta=1$, i.e. if manipulation is completely "undone" by the analysts, every manager would follow this strategy independently on her time 
preferences. In contrast, if the manager does not provide any guidance to the analysts with respect to the earnings she is planing to report, the manager with time preferences $\theta<\frac{1}{1+\delta}$ would choose to "borrow" earnings from the future, i.e. $\underline{m}=\bar{m}=m_{\max }$ as proved in Theorem 1. Both strategies are illustrated in Figure 3 .

Figure 3: Optimal Manipulation Strategies of a Manager Holding Shares with Guidance and No-Guidance

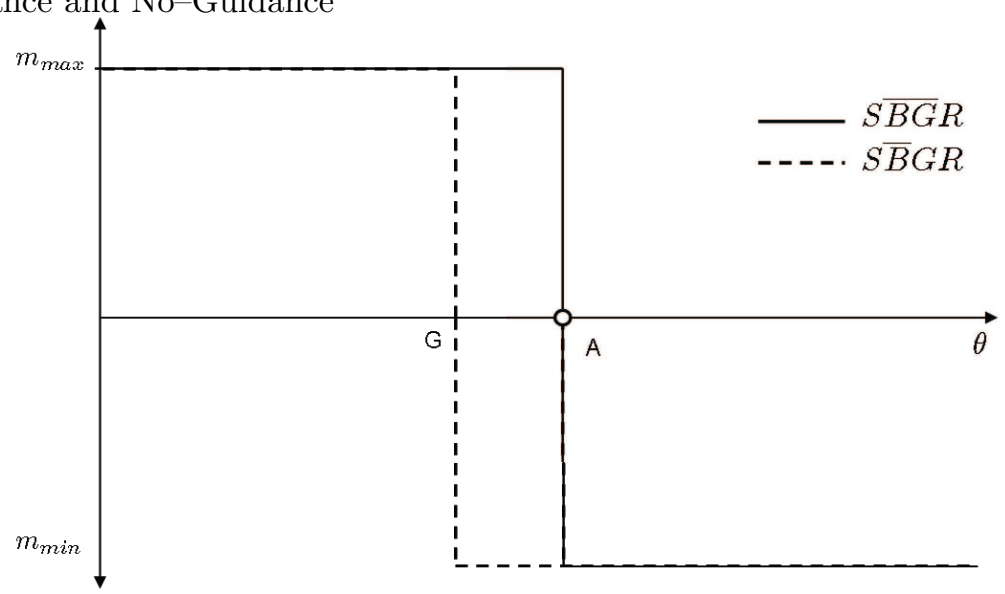

The figure summarizes the optimal manipulation strategies of a manager holding shares $(S)$, providing guidance $(G)$ or not $(\bar{G})$ in dependence on her time preferences $\theta$. The points $G=1-\delta$ and $A=\frac{1}{1+\delta}$ represent bounds for the time preferences $\theta$ for which the manipulation strategies are part of the revealing $(\bar{R})$ equilibria proved in Theorem 1 and 6 .

To make the difference in the manipulation policy of the manager more intuitive, assume that the time value of money is equal to zero, i.e. $\delta=1$. Then, the manager selling more shares in period $t$, i.e. $\theta<\frac{1}{2}$, would manage earnings up, i.e. $\bar{m}=\underline{m}=m_{\max }$ if she does not guide. The same manager would follow a different strategy if she guides the analysts. This manager would anticipate that the analysts' reaction offsets the price effect of the earnings manipulation in the current period and decide to "save" earnings, i.e. $\bar{m}=\underline{m}=m_{\min }$ for the future instead. In both cases the manager would report truthfully if she is indifferent between selling shares in the current and the last period, i.e. $\theta=\frac{1}{2}$.

Overall, if the manager holdings shares provides guidance to the analysts, the absolute level of manipulation in the economy does not change. The effect of guidance limits to more "big baths" compared to the case where the manager does not communicate her reporting plans.

In the following, we analyze the effect of guidance on the absolute level of manipulation and the number of "big baths" in the economy if the managers in that economy hold stock options instead of shares.

Theorem 7 ( $C \bar{B} G R$ reporting). If the manager holds stock options, $v()=$.0 , and guides the analysts we obtain the following equilibria.

For $\theta \in\left[\frac{(2-p-\delta)(\bar{x}-\underline{x})+\delta X}{(2-p)(\bar{x}-\underline{x})+\delta X} ; 1\right]$

$\bar{m}^{*}=\underline{m}^{*}=m_{\text {min }}$ 
$F_{t}^{*}=p \bar{x}+(1-p) \underline{x}+m_{\text {min }}$

$\bar{F}_{t+1}^{*}=\underline{F}_{t+1}^{*}=p \bar{x}+(1-p) \underline{x}-m_{\text {min }}$

$\bar{C}_{t}^{*}=\underline{C}_{t}^{*}=0$

$\bar{C}_{t+1}^{*}=\bar{x}-m_{\min }-X$

$\underline{C}_{t+1}^{*}=\underline{x}-m_{\min }-X$

and the posterior beliefs of the analysts $\mu \in[0,1]$ is a revealing Bayesian equi-

librium (in pure strategies).

For $\theta \in\left[0, \frac{2(1-p)+\delta(2 p-3)}{2(1-p)+\delta(2 p-1)}\right]$ and $\delta<\frac{2 p-2}{2 p-3}$

$\bar{m}^{*}=\underline{m}^{*}=m_{\max }$

$F_{t}^{*}=p \bar{x}+(1-p) \underline{x}+m_{\max }$

$\bar{F}_{t+1}^{*}=\underline{F}_{t+1}^{*}=p \bar{x}+(1-p) \underline{x}-m_{\max }$

$\bar{C}_{t}^{*}=\bar{x}+m_{\max }+\delta\left(p \bar{x}+(1-p) \underline{x}-m_{\max }\right)-X$

$\underline{C}_{t}^{*}=\underline{x}+m_{\max }+\delta\left(p \bar{x}+(1-p) \underline{x}-m_{\max }\right)-X$

$\bar{C}_{t+1}^{*}=\underline{C}_{t+1}^{*}=0$

and the posterior beliefs of the analysts $\mu \in[0,1]$ is a revealing Bayesian equilibrium (in pure strategies).

Given that the analysts predict that the manager does not manipulate the earnings, it is never optimal for the manager to do so, when she holds stock options instead of shares. Thus, in equilibrium, the analysts would change their beliefs, which again influence the present value of the firm's earnings. The manager anticipates that any manipulation is almost "undone" in period $t$ and would "save" earnings for the the future if she has stronger preferences to exercise options in period $t+1$ compared to the case when she does not provide any guidance.

Therefore, in the case where the managers in the economy hold stock options their decision to guide the analysts has two effects. First, there will be more managers taking the "big bath" compared to the case with no guidance. Second, the absolute level of manipulation in the economy would increase. Both effects are illustrated in Figure 4. 
Figure 4: Optimal Manipulation Strategies of a Manager Holding Stock Options with Guidance and No-Guidance

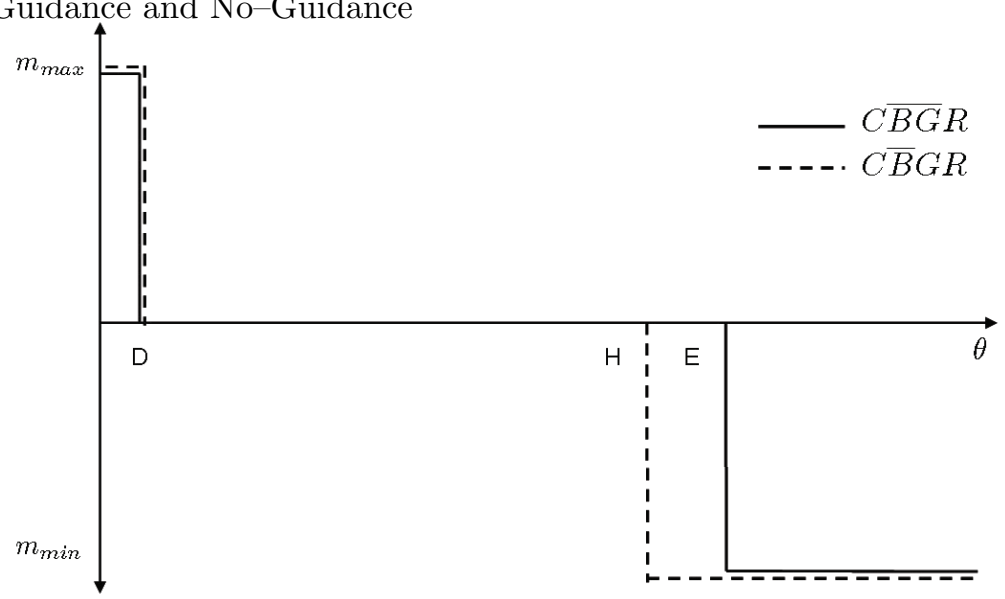

The figure summarizes the optimal manipulation strategies of a manager holding stock options $(C)$, providing guidance $(G)$ or not $(\bar{G})$ in dependence on her time preferences $\theta$. The points $E=\frac{2}{2+\delta}$ and $H=\frac{(2-p-\delta)(\bar{x}-\underline{x})+\delta X}{(2-p)(\bar{x}-x) 1 \delta X}$ represent bounds for the time preferences $\theta$ for which the manipulation strategies are part of the revealing $(R)$ equilibria proved in Theorem 1 and 6 .

Having derived conclusions on the effect of guidance on the number of "big baths" and the absolute level of manipulation in the economy, we focus now on the effect of managers' compensation when the managers in that economy guide. We have already seen that the absolute level of manipulation in the economy is lower if the managers providing no guidance are compensated with shares than with stock options. The same conclusion holds also for managers providing guidance. The absolute level of manipulation is lower if the managers are compensated with stock options than with shares, since $\frac{2(1-p)+\delta(2 p-3)}{2(1-p)+\delta(2 p-1)}<$ $1-\delta<\frac{(2-p-\delta)(\bar{x}-\underline{x})+\delta X}{(2-p)(\bar{x}-x) 1 \delta X}$ (see Theorem 6 and 7 ). Figure 5 illustrates the effect graphically. 
Figure 5: Optimal Manipulation Strategies of a Manager Providing Guidance and Holding Shares or Stock Options

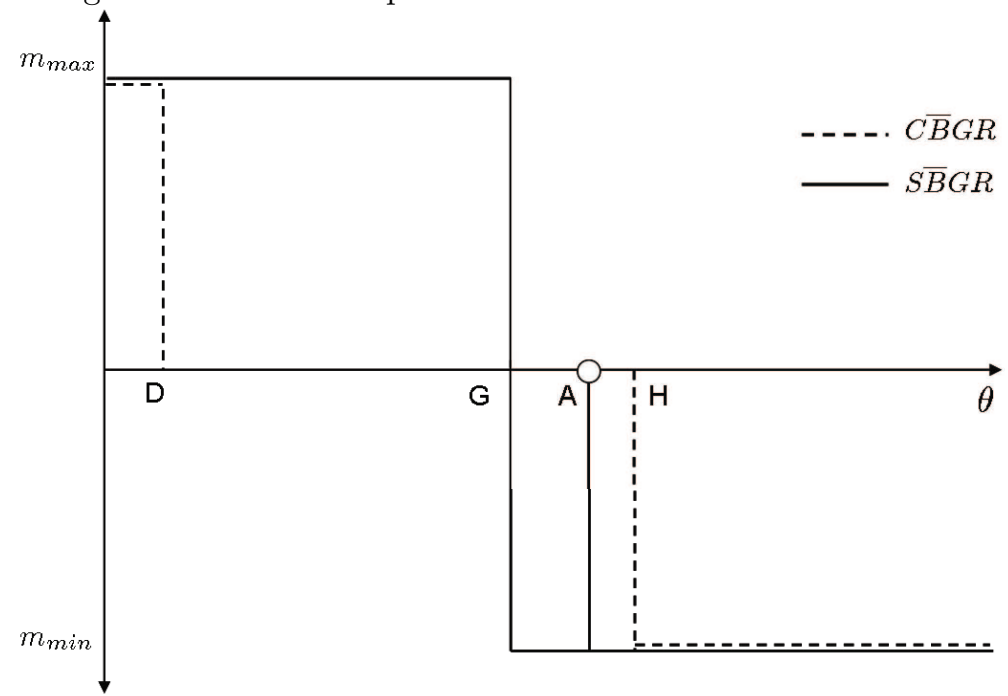

The figure summarizes the optimal manipulation strategies of a manager holding shares $(S)$ or stock options $(C)$ and providing guidance $(G)$ in dependence on her time preferences $\theta$. The points $A=\frac{1}{1+\delta}, D=\frac{2(1-p)+\delta(2 p-3)}{2(1-p)+\delta(2 p-1)}, G=1-\delta$, and $H=\frac{(2-p-\delta)(\bar{x}-\underline{x})+\delta X}{(2-p)(\bar{x}-\underline{x}) 1 \delta X}$ represent bounds for the time preferences $\theta$ for which the manipulation strategies are part of the revealing $(R)$ equilibria proved in Theorem 6 and 7 .

\section{Conclusions}

The question whether and why managers manipulate earnings has been one of the main research issues in several empirical and theoretical papers lately. Their main point is that the managers' manipulation decisions are basically motivated by the investors' response to earnings reports. This raises the question whether the managers' incentives to manipulate earnings change if firm's outsiders behave strategically when observing the managers' reporting decisions and determine the price of the firm's shares.

To analyze this problem we consider a three-period economy with one manager, investors and analysts that interact strategically. The main objective of our model is to support to derive conclusions on how the market conditions, the manager's compensation package and the manager's guidance to analysts affect the manager's incentives to manipulate earnings and ultimately the absolute level of manipulation in the whole economy. Based on the analytical results, we can derive the following conclusions.

When evaluating the relevance of the market conditions we distinguish two cases. The first one is the case where investors consider analysts only as providers of information regarding the next period earnings that the manager is reporting. The second one is the case where investors are behavioral, i.e. they consider the analysts' forecasts as a reference point when evaluating the earnings reported by the manager. Our results show that whatever the compen- 
sation package of the managers, the fact that the managers play the earnings game with behavioral investors does not increase the absolute level of manipulation in the economy. The reason is that in the case of behavioral investors and managers holding shares, some managers would choose to manipulate the earnings in order to meet the analysts' forecasts. This manipulation is per definition lower than the minimum and maximum bounds of manipulation representing earnings reserves that managers can shift over time. In contrast, if the managers in the economy hold stock options, they would not choose to meet the analysts' forecasts in equilibrium. Instead, they would prefer to shift all there earnings reserves over time. Since this strategy is optimal for less managers when investors are behavioral compared to the case with non-behavioral investors, we can conclude that the loss aversion of the investors does not motivate more managers to shift their earnings reserves over time. In other words, the absolute level of manipulation decreases if managers holding shares instead of stock options play the earnings game with investors who are additionally averse against earnings reports below the consensus forecast.

When assessing the impact of the managers' compensation, we consider a manager holding either shares or stock options. Independent on whether the investors are behavioral or not, the absolute level of manipulation in the economy is lower if the managers in the economy hold stock options than shares. The same conclusion holds also if the managers in the economy provide guidance to analysts and investors are non-behavioral.

The impact of guidance is studied in an economy with managers holding shares and stock options. Independently on their compensation package, there are more managers taking the "big bath" if they guide the analysts compared to the case with no guidance. Since this does not influence the overall level of manipulation in the economy when managers hold stocks, there will be more manipulation if managers hold stock options and guide the analysts compared to the case with no-guidance.

Overall, if regulators aim to reduce the absolute level of manipulation in an economy, they should not try to motivate investors to focus only on the present value of earnings. Instead, they should support the investors' view that earnings reports should be additionally evaluated relative to the consensus forecast, and managers reporting earnings below it, should be punished by a stronger price decline compared to managers beating the consensus by the same amount. When evaluating the advantages and disadvantages of managers' compensation packages, regulators should also support managers compensation plan based on stock options instead of shares. Ultimately, if the managers in the economy are compensated with stock options earnings guidance should be abolished by regulators since this increases the absolute level of manipulation in the economy.

Our model can be extended in several aspects. First, it would be interesting to see how the results change if we consider a strategic game without a final period. Second, it might be relevant to observe how the managers' incentives to manipulate earnings change if investors behave strategically as well. Finally, introducing other firms competing for the investors' attention may also have interesting implications for the manipulation behavior of the managers in an economy with behavioral investors. 


\section{References}

[1] Barth, M.E., J.A. Elliot, and M.W. Finn, 1999. Market Reward Associated with Patterns of Increasing Earnings. Journal of Accounting Research 37 (Autumn), 387-413

[2] Bartov, E, D. Givoly, C. Hayn, 2002. The Reward of Meeting or Beating Earnings Expectations. Journal of Accounting and Economics 33 (June), 173-204

[3] Burgstahler, D. and I. Dichev, 1997. Earnings Management to Avoid Earnings Decreases and Losses. Journal of Accounting and Economics 24 (December), 99-126

[4] Chaney, P.K. and C.M. Lewis, 1994. Earnings Management and Firm Valuation Under Asymmteric Information. Journal of Corporate Finance 1, $319-245$

[5] Degeorge, F., J. Patel and R. Zeckhauser, 1999. Earnings Management to Exceed Thresholds. Journal of Business 72 (1), 1-33

[6] Fischer, P.E. and R.E. Verrecchia, 2000. Reporting Bias. The accounting Review 75 (2), 229-245

[7] Freeman, R. N. and S. Y. Tse, 1992. A Nonlinear Model of Security Price Responses to Unexpected Earnings. Journal of Accounting Research 20 (2), 185-209

[8] Graham, J.R., Harvey, C.R., and S. Rajgopal, 2005. The Economic Implications of Corporate Financial Reporting. Journal of Accounting and Economics 10 (1-3), 3-73

[9] Guttman, I., O. Kadan and E. Kandel, 2004. A Rational Expectations Theory of the Kink in Earnings Reports. Working Paper

[10] Hong, J. and J. Kubik, 2003. Analyzing the Analysts: Career Concerns and Biased Earnings Forecasts. Journal of Finance 58, 313-351

[11] Kasznik, R. and M.F. McNichols, 2002. Does Meeting Earnings Expectations Matter? Evidence From Analyst Forecast Revisions and Share Prices. Journal of Acconting Research 40 (3), 727-759

[12] Kinney, W. D. Burgstahler, and R. Martin, 2001. The Materiality of Earnings Surprise. Working paper

[13] Matsumoto, D.A., 2002. Management's Incentives to Avoid Negative Earnings Surprises. The Accounting Review 77 (3), July

[14] Matsunaga, S.R. and C.W. Park, 2001. The Effect of Missing a Quarterly Earnings Benchmark on the CEO's annual bonus. The Accounting Review $76,313-332$

[15] Myers, L. and D. Skinner, 2001. Earnings momentum and earnings management. Working paper, University of Michigan. 
[16] Tversky, A. and D. Kahneman, 1979. Prospect Theory: an Analysis of Decision Under Risk. Econometrica 47, 263-292

[17] Skinner, D. and R. Sloan, 2002. Earnings Surprises, Growth Expectations, and Stock Returns or Dont Let an Earnings Torpedo Sink Your Portfolio. Review of Accounting Studies 7, 289-312

[18] Stein, J., 1989. Efficient Capital Markets, Ineffcient Firms: A Model of Myopic Corporate Behavior. The Quarterly Journal of Economics 104 (4), 655-669

[19] Trueman, B. and S. Titman, 1988. An Explamation of Accounting Income Smoothing. Journal of Accounting Research 26 (supplement 1988), 127139 


\section{A Appendix}

\section{A.1 Proof of Theorem 1}

The optimal forecasts of the analysts given their payoff function (7) are:

$$
F_{t}^{*}=p \bar{x}+(1-p) \underline{x}+p \bar{n}^{*}+(1-p) \underline{n}^{*}
$$

and

$$
F_{t+1}^{*}=p \bar{x}+(1-p) \underline{x}-\mu \bar{n}^{*}-(1-\mu) \underline{n}^{*}
$$

Then, the manager's payoff given that $x_{t}=\bar{x}$ is:

$$
\bar{u}(.)^{M}=(1-\theta)[\bar{x}+\bar{m}+\delta(p \bar{x}+(1-p) \underline{x})-\delta \bar{n}]+\delta \theta p(\bar{x}-\bar{m})+\delta \theta(1-p)(\underline{x}-\bar{m})
$$

and given that $x_{t}=\underline{x}$ is:

$$
\left.\underline{u}(.)^{M}=(1-\theta)[\underline{x}+\underline{m}+\delta(p \bar{x}+(1-p) \underline{x})-\delta \underline{n}]+\delta \theta p(\bar{x}-\underline{m})+\delta \theta(1-p) 8 \underline{x}-\underline{m}\right)
$$

Since the manager's payoff is increasing in $\bar{m}$ respectively $\underline{m}$, the manager would choose the extreme strategies $\bar{m}=\underline{m}=m_{\max }\left(\right.$ respectively $\bar{m}=\underline{m}=m_{\min }$ ). If the manager is indifferent between manipulating earnings or truthful reporting, we assume that she chooses $\bar{m}=\underline{m}=0$.

Comparing the manager's payoff associated with the different strategies we get that the manager's payoff is maximal if

$$
\bar{m}=\underline{m}=m_{\max }>0 \text { and } \theta<\frac{1}{1+\delta}
$$

or

$$
\bar{m}=\underline{m}=m_{\min }<0 \text { and } \theta>\frac{1}{1+\delta}
$$

If $\theta=\frac{1}{1+\delta}$, the manager is indifferent between manipulating the earnings and truthful reporting. The analysts' beliefs are correct and given these beliefs the manager does not have incentives to follow a different strategy, i.e. $\bar{m}=\bar{n}=$ $\underline{m}=\underline{n}=0$.

If the manager prefers to manipulate the earnings, the analysts adjust their beliefs accordingly, so that in equilibrium $\bar{m}=\underline{m}=\bar{n}=\underline{n}=m_{\min }$ respectively $\bar{m}=\underline{m}=\bar{n}=\underline{n}=m_{\max }$ for any $\mu \in[0,1]$. If for example $\bar{n}=\underline{n}=m_{\max }$, the manager's payoffs in both states are:

$$
\bar{u}(.)^{M}=(1-\theta)\left[\bar{x}+\bar{m}+\delta\left(p \bar{x}+(1-p) \underline{x}-m_{\max }\right)\right]+\delta \theta p[\bar{x}-\bar{m}]+\delta \theta(1-p)[\underline{x}-\bar{m}]
$$

respectively

$\underline{u}(.)^{M}=(1-\theta)\left[\underline{x}+\underline{m}+\delta\left(p \bar{x}+(1-p) \underline{x}-m_{\max }\right)\right]+\delta \theta p(\bar{x}-\underline{m})+\delta \theta(1-p)(\underline{x}-\underline{m})$

Then, the manager would compare her payoffs from different manipulation strategies $m \in\left[m_{\min }, m_{\max }\right]$ and would choose the strategy delivering the maximum payoff. If the analysts choose $\bar{n}=\underline{n}=m_{\max }$ the manager's payoff is maximal if she plays $\bar{m}=\underline{m}=m_{\max }$ given that $\theta<\frac{1}{1+\delta}$. Similarly, the manager's payoff from following the strategy $\bar{m}=\underline{m}=m_{\min }$ given that the analysts choose $\bar{n}=\underline{n}=m_{\min }$ is maximal if $\theta>\frac{1}{1+\delta}$. If $\theta=\frac{1}{1+\delta}$, the manager is indifferent between manipulating earnings and truthful reporting and she chooses $\bar{m}=\underline{m}=0$. 


\section{A.2 Proof of Theorem 2}

Suppose that in this equilibrium the best response of the analysts is $F_{t}^{*}=$ $F_{t+1}^{*}=p \bar{x}+(1-p) \underline{x}$. Later on, we are proving this claim.

Given the beliefs of the analysts, the payoffs of the manager in both states are:

$$
\begin{aligned}
\bar{u}^{M}(.)= & (1-\theta)[\bar{x}+\bar{m}+\delta(p \bar{x}+(1-p) \underline{x})+v(\bar{x}+\bar{m}-p \bar{x}-(1-p) \underline{x})] \\
& +\delta \theta p[\bar{x}-\bar{m}+v(\bar{x}-\bar{m}-p \bar{x}-(1-p) \underline{x})] \\
& +\delta \theta(1-p)[\underline{x}-\bar{m}+v(\underline{x}-\bar{m}-p \bar{x}-(1-p) \underline{x})]
\end{aligned}
$$

respectively

$$
\begin{aligned}
\underline{u}^{M}(.)= & (1-\theta)[\underline{x}+\underline{m}+\delta(p \bar{x}+(1-p) \underline{x})+v(\underline{x}+\underline{m}-p \bar{x}-(1-p) \underline{x})] \\
& +\delta \theta p[\bar{x}-\underline{m}+v(\bar{x}-\underline{m}-p \bar{x}-(1-p) \underline{x})] \\
& +\delta \theta(1-p)[\underline{x}-\underline{m}+v(\underline{x}-\underline{m}-p \bar{x}-(1-p) \underline{x})]
\end{aligned}
$$

Now, we consider different levels of manipulation for which the marginal utility change and compare the manager's payoffs associated with them. For $F_{t}^{*}=$ $F_{t+1}^{*}=p \bar{x}+(1-p) \underline{x}$ the manipulation decisions changing the marginal utility of manipulation are:

$$
\begin{aligned}
& \bar{m}_{1}=m_{\min } \\
& \bar{m}_{2}=\underline{x}-p \bar{x}-(1-p) \underline{x}=-p(\bar{x}-\underline{x}) \\
& \bar{m}_{3}=p \bar{x}+(1-p) \underline{x}-\bar{x}=-(1-p)(\bar{x}-\underline{x}) \\
& \bar{m}_{4}=0 \\
& \bar{m}_{5}=\bar{x}-p \bar{x}-(1-p) \underline{x}=(1-p)(\bar{x}-\underline{x}) \\
& \bar{m}_{6}=m_{\max }
\end{aligned}
$$

respectively

$$
\begin{aligned}
\underline{m}_{1} & =m_{\min } \\
\underline{m}_{2} & =\underline{x}-p \bar{x}-(1-p) \underline{x}=-p(\bar{x}-\underline{x}) \\
\underline{m}_{3} & =0 \\
\underline{m}_{4} & =\bar{x}-p \bar{x}-(1-p) \underline{x}=(1-p)(\bar{x}-\underline{x}) \\
\underline{m}_{5} & =p \bar{x}-(1-p) \underline{x}-\underline{x}=p(\bar{x}-\underline{x}) \\
\underline{m}_{6} & =m_{\max }
\end{aligned}
$$

Thus, to prove that the manipulation strategies $\bar{m}_{3}=-(1-p)(\bar{x}-\underline{x})$ and $\underline{m}_{5}=p(\bar{x}-\underline{x})$ are the best given that $F_{t}^{*}=F_{t+1}^{*}=p \bar{x}+(1-p) \underline{x}$ we need to prove that the manager cannot increase her payoff by following a different strategy given the beliefs of the analysts. To define the conditions for which this is true, we compare the manager's payoffs associated with the different manipulation strategies.

Consider first the case where $x_{t}=\bar{x}$. Then, the manager's payoffs associated with the manipulation strategies changing the marginal utility of manipulation 
in this state are:

$$
\begin{aligned}
\bar{u}_{1}^{M}\left(\bar{m}=m_{\text {min }}\right)= & (1-\theta)\left[\bar{x}+m_{\min }+\delta(p \bar{x}+(1-p) \underline{x})\right. \\
& \left.+\beta\left(\bar{x}+m_{\text {min }}-p \bar{x}-(1-p) \underline{x}\right)\right] \\
& +\delta \theta p\left(\bar{x}-m_{\text {min }}+\bar{x}-m_{\text {min }}-p \bar{x}-(1-p) \underline{x}\right) \\
& +\delta \theta(1-p)\left[\underline{x}-m_{\text {min }}+\underline{x}-m_{\text {min }}-p \bar{x}-(1-p) \underline{x}\right]
\end{aligned}
$$

$$
\begin{aligned}
\bar{u}_{2}^{M}(\bar{m}=-p(\bar{x}-\underline{x}))= & (1-\theta)[\bar{x}-p(\bar{x}-\underline{x})+\delta(p \bar{x}+(1-p) \underline{x}) \\
& +\beta(\bar{x}-p(\bar{x}-\underline{x})-p \bar{x}-(1-p) \underline{x})] \\
& +\delta \theta p(\bar{x}+p(\bar{x}-\underline{x})+\bar{x}+p(\bar{x}-\underline{x})-p \bar{x}-(1-p) \underline{x}) \\
& +\delta \theta(1-p)(\underline{x}+p(\bar{x}-\underline{x}))
\end{aligned}
$$

$$
\begin{aligned}
\bar{u}_{3}^{M}(\bar{m}=-(1-p)(\bar{x}-\underline{x}))= & (1-\theta)[\bar{x}-(1-p)(\bar{x}-\underline{x})+\delta(p \bar{x}+(1-p) \underline{x})] \\
& +\delta \theta p[\bar{x}+(1-p)(\bar{x}-\underline{x}) \\
& +\bar{x}+(1-p)(\bar{x}-\underline{x})-p \bar{x}-(1-p) \underline{x}] \\
& +\delta \theta(1-p)[\underline{x}+(1-p)(\bar{x}-\underline{x}) \\
& +\beta(\underline{x}+(1-p)(\bar{x}-\underline{x})-p \bar{x}-(1-p) \underline{x})]
\end{aligned}
$$

$$
\begin{aligned}
\bar{u}_{4}^{M}(\bar{m}=0)= & (1-\theta)[\bar{x}+\delta(p \bar{x}+(1-p) \underline{x})+\bar{x}-p \bar{x}-(1-p) \underline{x}] \\
& +\delta \theta p[\bar{x}+\bar{x}-p \bar{x}-(1-p) \underline{x}] \\
& +\delta \theta(1-p)[\underline{x}+\beta(\underline{x}-p \bar{x}-(1-p) \underline{x})]
\end{aligned}
$$

$$
\begin{aligned}
\bar{u}_{5}^{M}(\bar{m}=(1-p)(\bar{x}-\underline{x}))= & (1-\theta)[\bar{x}+(1-p)(\bar{x}-\underline{x})+\delta(p \bar{x}+(1-p) \underline{x}) \\
& +\bar{x}+(1-p)(\bar{x}-\underline{x})-p \bar{x}-(1-p) \underline{x}] \\
& +\delta \theta p[\bar{x}-(1-p)(\bar{x}-\underline{x})] \\
& +\delta \theta(1-p)[\underline{x}-(1-p)(\bar{x}-\underline{x}) \\
& +\beta(\underline{x}-(1-p)(\bar{x}-\underline{x})-p \bar{x}-(1-p) \underline{x})]
\end{aligned}
$$

$$
\begin{aligned}
\bar{u}_{6}^{M}\left(\bar{m}=m_{\max }\right)= & (1-\theta)\left[\bar{x}+m_{\max }+\delta(p \bar{x}+(1-p) \underline{x})\right. \\
& \left.+\bar{x}+m_{\max }-p \bar{x}-(1-p) \underline{x}\right] \\
& +\delta \theta p\left[\bar{x}-m_{\max }+\beta\left(\bar{x}-m_{\max }-p \bar{x}-(1-p) \underline{x}\right)\right] \\
& +\delta \theta(1-p)\left[\underline{x}-m_{\max }+\beta\left(\underline{x}-m_{\max }-p \bar{x}-(1-p) \underline{x}\right)\right]
\end{aligned}
$$

The strategy $\bar{m}_{3}=-(1-p)(\bar{x}-\underline{x})$ is optimal for the managers if (31) is larger than $(29),(30),(32),(33)$ and (34). We derive conditions on $\theta$ depending on the 
parameters $p, \delta$ and $\beta$ for which this is true. These conditions are illustrated in Figure 6 as manifolds under the assumption that $\delta=0.95$ and $m_{\max }=2 \bar{x}$.

Figure 6: Restrictions on $\theta$ satisfying the equilibrium conditions for the case $x_{t}=\bar{x}$

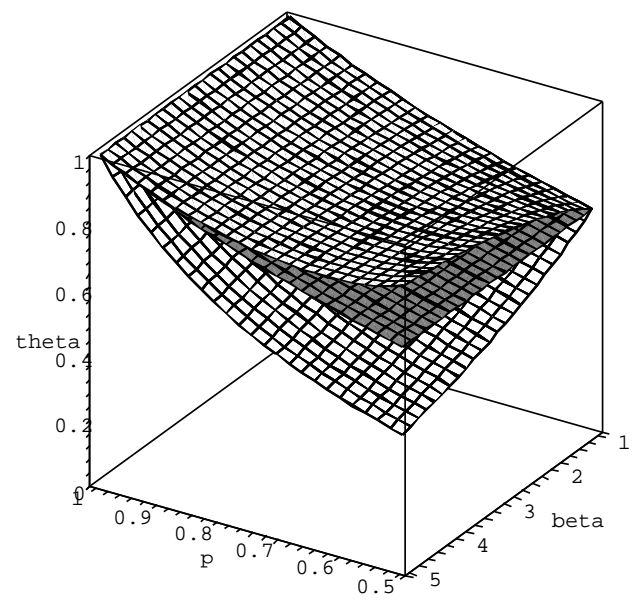

The two-dimensional manifolds determine the subsets of parameters for which certain payoffs are equal. The subset of parameters under the top manifold are such that (31) is greater than (29). The subset of parameters under the middle manifold are such that (31) is greater than (30). The subset of parameters above the lowest manifold are such that (31) is greater than (32), (33) and (34).

Thus, the upper bound of the parameter $\theta$ is determined by the condition that (31) is lower than (30) and the lower bound of the parameter $\theta$ is determined by the condition that (31) is greater than (32). This is equivalent to the condition

$$
\frac{2}{2+\delta(1+p)+\delta \beta(1-p)} \leq \theta \leq \frac{1+\beta}{(1+\beta)(1+\delta)+\delta p(1-\beta)}
$$

Consider next the case, where $x_{t}=\underline{x}$. Then, the manager's payoffs associated with the manipulation strategies in this state are:

$$
\begin{aligned}
\underline{u}_{1}^{M}\left(\underline{m}=m_{\text {min }}\right)= & (1-\theta)\left[\underline{x}+m_{\min }+\delta(p \bar{x}+(1-p) \underline{x})\right. \\
& \left.+\beta\left(\underline{x}+m_{m i n}-p \bar{x}-(1-p) \underline{x}\right)\right] \\
& +\delta \theta p\left(\bar{x}-m_{m i n}+\bar{x}-m_{m i n}-p \bar{x}-(1-p) \underline{x}\right) \\
& +\delta \theta(1-p)\left(\underline{x}-m_{m i n}+\underline{x}-m_{m i n}-p \bar{x}-(1-p) \underline{x}\right)
\end{aligned}
$$

$$
\begin{aligned}
\underline{u}_{2}^{M}(\underline{m}=-p(\bar{x}-\underline{x}))= & (1-\theta)[\underline{x}-p(\bar{x}-\underline{x})+\delta(p \bar{x}+(1-p) \underline{x}) \\
& +\beta(\underline{x}-p(\bar{x}-\underline{x})-p \bar{x}-(1-p) \underline{x})] \\
& +\delta \theta p[\bar{x}+p(\bar{x}-\underline{x})+\bar{x}+p(\bar{x}-\underline{x})-p \bar{x}-(1-p) \underline{x}] \\
& +\delta \theta(1-p)[\underline{x}+p(\bar{x}-\underline{x})]
\end{aligned}
$$




$$
\begin{aligned}
\underline{u}_{3}^{M}(\underline{m}=0)= & (1-\theta)[\underline{x}+\delta(p \bar{x}+(1-p) \underline{x})+\beta(\underline{x}-p \bar{x}-(1-p) \underline{x})] \\
& +\delta \theta p(\bar{x}+\bar{x}-p \bar{x}-(1-p) \underline{x}) \\
& +\delta \theta(1-p)[\underline{x}+\beta(\underline{x}-p \bar{x}-(1-p) \underline{x})]
\end{aligned}
$$

$$
\begin{aligned}
\underline{u}_{4}^{M}(\underline{m}=(1-p)(\bar{x}-\underline{x}))= & (1-\theta)[\underline{x}+(1-p)(\bar{x}-\underline{x})+\delta(p \bar{x}+(1-p) \underline{x}) \\
& +\beta(\underline{x}+(1-p)(\bar{x}-\underline{x})-p \bar{x}-(1-p) \underline{x})] \\
& +\delta \theta p[\bar{x}-(1-p)(\bar{x}-\underline{x})+\bar{x}] \\
& +\delta \theta(1-p)[\underline{x}-(1-p)(\bar{x}-\underline{x}) \\
& +\beta(\underline{x}-(1-p)(\bar{x}-\underline{x})-p \bar{x}-(1-p) \underline{x})]
\end{aligned}
$$

$$
\begin{aligned}
\underline{u}_{5}^{M}(\underline{m}=p(\bar{x}-\underline{x}))= & (1-\theta)[\underline{x}+p(\bar{x}-\underline{x})+\delta(p \bar{x}+(1-p) \underline{x}) \\
& +\delta \theta p[\bar{x}-p(\bar{x}-\underline{x})+\beta(\bar{x}-p(\bar{x}-\underline{x})-p \bar{x}-(1-p) \underline{x})] \\
& +\delta \theta(1-p)[\underline{x}-p(\bar{x}-\underline{x})+\beta(\underline{x}-p(\bar{x}-\underline{x})-p \bar{x}-(1-p) \underline{x})]
\end{aligned}
$$

$$
\begin{aligned}
\underline{u}_{6}^{M}\left(\underline{m}=m_{\max }\right)= & (1-\theta)\left[\underline{x}+m_{\max }+\delta(p \bar{x}+(1-p) \underline{x})\right. \\
& \left.+\underline{x}+m_{\max }-p \bar{x}-(1-p) \underline{x}\right] \\
& +\delta \theta p\left[\bar{x}-m_{\max }+\beta\left(\bar{x}-m_{\max }-p \bar{x}-(1-p) \underline{x}\right)\right] \\
& +\delta \theta(1-p)\left[\underline{x}-m_{\max }+\underline{x}-m_{\max }-p \bar{x}-(1-p) \underline{x}\right]
\end{aligned}
$$

The strategy $\underline{m}_{5}=p(\bar{x}-\underline{x})$ is optimal for the manager if (40) is larger than (36), (37), (38), (39) and (41). We derive conditions on $\theta$ depending on the parameters $p, \delta$ and $\beta$ for which this is true. These conditions are illustrated in Figure 7 as manifolds under the assumption that $\delta=0.95$ and $m_{\max }=2 \bar{x}$. 
Figure 7: Restrictions on $\theta$ satisfying the equilibrium conditions for the case $x_{t}=\underline{x}$

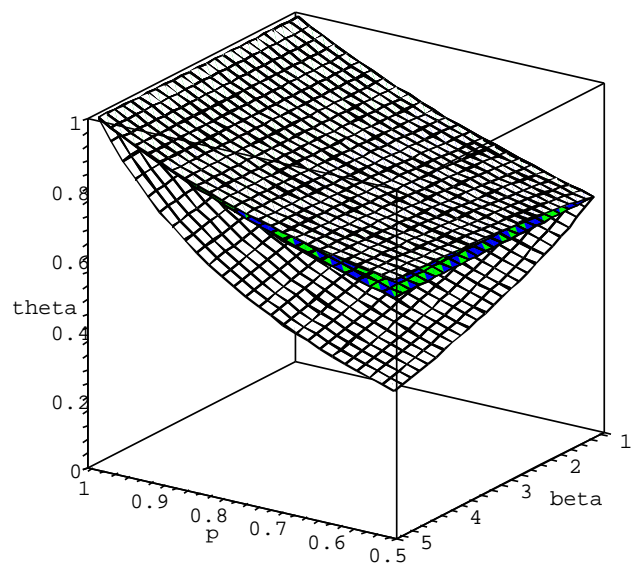

The two-dimensional manifolds determine the subsets of parameters for which certain payoffs are equal. The subset of parameters under the top manifold are such that (40) is greater than (36). The subset of parameters under the middle manifold are such that (40) is greater than (37), (38) and (39). The subset of parameters above the lowest manifold are such that (40) is greater than (41).

Thus, the strategy $\underline{m}_{5}=p(\bar{x}-\underline{x})$ is optimal for the manager if (40) is larger than (38) and (41). This is true for

$$
\frac{-2\left(m_{\max }-p(\bar{x}-\underline{x})\right)}{2 p+\delta p(1+\beta)-m_{\max }(2+\delta(1+\beta))} \leq \theta \leq \frac{1}{1+\delta}
$$

If $m_{\max }=\bar{x}-\underline{x}$ for example, then the condition is equivalent to:

$$
\frac{2}{2+\delta(1+\beta)} \leq \theta \leq \frac{1}{1+\delta}
$$

Comparing the conditions (35) and (43), one can see that the lower bound for the parameter $\theta$ is determined by condition (35) and the upper bound for the parameter $\theta$ is determined by condition (43) so that for $\frac{2}{2+\delta(1+p)+\delta \beta(1-p)} \leq$ $\theta \leq \frac{1}{1+\delta}$ the best strategy of the manager is to cover the consensus forecast, which is equal to the mean of the "true" earnings in this equilibrium.

Note that this strategy is optimal only if investors are loss averse. For $\beta \leq 1$ the conditions (35) and (43) are empty and the non-revealing equilibrium where the manager manipulates earnings to meet the consensus forecast would not exist.

Finally, we prove that given the best response of the manager, the best forecasts of the analysts is $F_{t}=\bar{F}_{t+1}=\underline{F}_{t+1}=p \bar{x}+(1-p) \underline{x}$. The optimal forecasts of the analysts given their payoff function (7) and the optimal manipulation de- 
cision of the manager are:

$$
\begin{aligned}
F_{t}^{*}=\bar{F}_{t+1}^{*}=\underline{F}_{t+1}^{*} & =p \bar{x}+(1-p) \underline{x}+p(1-p)(\underline{x}-\bar{x})+(1-p) p(\bar{x}-\underline{x} 44) \\
& =p \bar{x}+(1-p) \underline{x}
\end{aligned}
$$

since in this equilibrium $\mu=p$.

The optimal reporting strategy of the manager given that $F_{t}=F_{t+1}=$ $p \bar{x}+(1-p) \underline{x}$ is summarized graphically using a numerical example with $\bar{x}=1$, $\underline{x}=-1, p=0.6, \delta=0.95$.

Figure 8: Optimal Reporting if $x_{t}=\bar{x}$ and $x_{t}=\underline{x}$

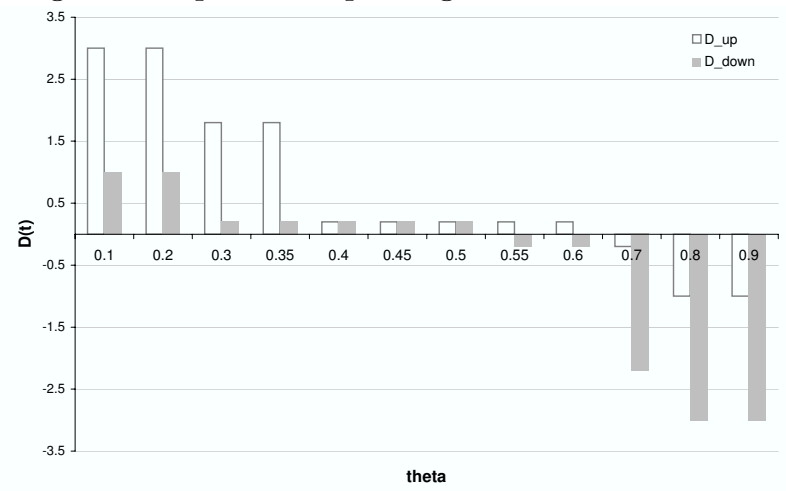

The figure summarizes the optimal reported earnings " $\mathrm{D}$ up" equal to $\bar{D}_{t}=\bar{x}+\bar{m}$ and "D down" equal to $\underline{D}_{t}=\underline{x}+\underline{m}$ given that $F_{t}=F_{t+1}=p \bar{x}+(1-p) \underline{x}$. The manager's optimal reporting is calculated for $\bar{x}=1, \underline{x}=-1, \beta=5, p=0.6$, $\delta=0.95$.

As one can easily see, the optimal manipulation strategy where $\bar{D}_{t}=\underline{D}_{t}$ results only for particular values of $\theta$. the upper and lower bound for $\theta$ are calculated above. For other values of $\theta \bar{D}_{t}$ is not equal to $\underline{D}_{t}$, so that the reporting is revealing in the sense that the analysts would adjust their beliefs in equilibrium. The chosen reporting might not be optimal anymore.

\section{A.3 Proof of Theorem 3}

Suppose that in the first equilibrium the best response of the analysts is $F_{t}=$ $p \bar{x}+(1-p) \underline{x}+m_{\max }$ and $\bar{F}_{t+1}=\underline{F}_{t+1}=p \bar{x}+(1-p) \underline{x}-m_{\max }$. later on, we are proving this claim.

Given the beliefs of the analysts, the manager's payoffs are:

$$
\begin{aligned}
\bar{u}^{M}(.)= & (1-\theta)\left[\bar{x}+\bar{m}+\delta\left(p \bar{x}+(1-p) \underline{x}-m_{\max }\right)+v\left(\bar{x}+\bar{m}-p \bar{x}-(1-p) \underline{x}+m_{\max }\right)\right] \\
& +\delta \theta p\left[\bar{x}-\bar{m}+v\left(\bar{x}-\bar{m}-p \bar{x}-(1-p) \underline{x}+m_{\max }\right)\right] \\
& +\delta \theta(1-p)\left[\underline{x}-\bar{m}+v\left(\underline{x}-\bar{m}-p \bar{x}-(1-p) \underline{x}+m_{\max }\right)\right]
\end{aligned}
$$

respectively

$$
\begin{aligned}
\underline{u}^{M}(.)= & (1-\theta)\left[\underline{x}+\underline{m}+\delta\left(p \bar{x}+(1-p) \underline{x}-m_{\max }\right)+v\left(\underline{x}+\underline{m}-p \bar{x}-(1-p) \underline{x}+m_{\max }\right)\right] \\
& +\delta \theta p\left[\bar{x}-\underline{m}+v\left(\bar{x}-\underline{m}-p \bar{x}-(1-p) \underline{x}+m_{\max }\right)\right] \\
& +\delta \theta(1-p)\left[\underline{x}-\underline{m}+v\left(\underline{x}-\underline{m}-p \bar{x}-(1-p) \underline{x}+m_{\max }\right)\right]
\end{aligned}
$$


Now, we consider different levels of manipulation for which the marginal utility of manipulation changes and compare the manager's payoff associated with them. Given the analysts' forecasts representing the reference point in the function $v($.$) the feasible manipulation levels m \in\left[m_{\min }, m_{\max }\right]$ for which the marginal utility of manipulation changes are:

$$
\begin{aligned}
& \bar{m}=m_{\max }-\bar{x}+p \bar{x}+(1-p) \underline{x} \\
& \bar{m}=m_{\max }+\underline{x}-p \bar{x}-(1-p) \underline{x} \\
& \underline{m}=m_{\max }+\underline{x}-p \bar{x}-(1-p) \underline{x}
\end{aligned}
$$

Note that given the analysts' forecasts, the manager is able to meet them in the current period only if $x_{t}=\bar{x}$. If $x_{t}=\underline{x}$, the manipulation required to meet the consensus forecast is not feasible since we assume that $m \in\left[m_{\min }, m_{\max }\right]$.

Overall, the manager can chose among the following strategies:

$$
\begin{aligned}
& \bar{m}_{1}=m_{\min } \\
& \bar{m}_{2}=0 \\
& \bar{m}_{3}=m_{\max }+\underline{x}-p \bar{x}-(1-p) \underline{x} \\
& \bar{m}_{4}=m_{\max }-\bar{x}+p \bar{x}+(1-p) \underline{x} \\
& \bar{m}_{5}=m_{\max }
\end{aligned}
$$

respectively

$$
\begin{aligned}
& \underline{m}_{1}=m_{\min } \\
& \underline{m}_{2}=0 \\
& \underline{m}_{3}=m_{\max }+\underline{x}-p \bar{x}-(1-p) \underline{x} \\
& \underline{m}_{4}=m_{\max }
\end{aligned}
$$

Consider first the case where $x_{t}=\bar{x}$. The manager's payoffs associated with the manipulation strategies listed above are as follows.

$$
\begin{aligned}
& \bar{u}_{1}^{M}(.)=(1-\theta)\left[\bar{x}+m_{\min }+\delta\left(p \bar{x}+(1-p) \underline{x}-m_{\max }\right)\right. \\
& \left.+\beta\left(\bar{x}+m_{\min }-p \bar{x}-(1-p) \underline{x}-m_{\max }\right)\right] \\
& +\delta \theta p\left[\bar{x}-m_{\min }+\bar{x}-m_{\min }-p \bar{x}-(1-p) \underline{x}+m_{\max }\right] \\
& +\delta \theta(1-p)\left[\underline{x}-m_{\min }+\underline{x}-m_{\min }-p \bar{x}-(1-p) \underline{x}+m_{\max }\right]( \\
& \bar{u}_{2}^{M}(.)=(1-\theta)\left[\bar{x}+\delta\left(p \bar{x}+(1-p) \underline{x}-m_{\max }\right)\right. \\
& \left.+\beta\left(\bar{x}-p \bar{x}-(1-p) \underline{x}-m_{\max }\right)\right] \\
& +\delta \theta p\left[\bar{x}+\bar{x}-p \bar{x}-(1-p) \underline{x}+m_{\max }\right] \\
& +\delta \theta(1-p)\left[\underline{x}+\underline{x}-p \bar{x}-(1-p) \underline{x}+m_{\max }\right] \\
& \bar{u}_{3}^{M}(.)=(1-\theta)\left[\bar{x}+m_{\max }+\underline{x}-p \bar{x}-(1-p) \underline{x}+\delta\left(p \bar{x}+(1-p) \underline{x}-m_{\max }\right)\right. \\
& \left.+\beta\left(\bar{x}+m_{\max }+\underline{x}-p \bar{x}-(1-p) \underline{x}-p \bar{x}-(1-p) \underline{x}-m_{\max }\right)\right] \\
& +\delta \theta p\left[\bar{x}-m_{\max }-\underline{x}+p \bar{x}+(1-p) \underline{x}\right. \\
& \left.+\bar{x}-m_{\max }-\underline{x}+p \bar{x}+(1-p) \underline{x}-p \bar{x}-(1-p) \underline{x}+m_{\max }\right] \\
& +\delta \theta(1-p)\left[\underline{x}-m_{\max }-\underline{x}+p \bar{x}+(1-p) \underline{x}\right]
\end{aligned}
$$




$$
\begin{aligned}
\bar{u}_{4}^{M}(.)= & (1-\theta)\left[\bar{x}+m_{\max }-\bar{x}+p \bar{x}+(1-p) \underline{x}+\delta\left(p \bar{x}+(1-p) \underline{x}-m_{\max }\right)\right] \\
& +\delta \theta p\left[\bar{x}-m_{\max }+\bar{x}-p \bar{x}-(1-p) \underline{x}\right. \\
& \left.+\bar{x}-m_{\max }+\bar{x}-p \bar{x}-(1-p) \underline{x}-p \bar{x}-(1-p) \underline{x}+m_{\max }\right] \\
& +\delta \theta(1-p)\left[\underline{x}-m_{\max }+\bar{x}-p \bar{x}-(1-p) \underline{x}\right. \\
+ & \left.\beta\left(\underline{x}-m_{\max }+\bar{x}-p \bar{x}-(1-p) \underline{x}-p \bar{x}-(1-p) \underline{x}+m_{\max }\right)\right] \\
\bar{u}_{5}^{M}(.)= & (1-\theta)\left[\bar{x}+m_{\max }+\delta\left(p \bar{x}+(1-p) \underline{x}-m_{\max }\right)\right. \\
& \left.+\bar{x}+m_{\max }-p \bar{x}-(1-p) \underline{x}-m_{\max }\right] \\
& +\delta \theta p\left[\bar{x}-m_{\max }+\bar{x}-m_{\max }-p \bar{x}-(1-p) \underline{x}+m_{\max }\right] \\
& +\delta \theta(1-p)\left[\underline{x}-m_{\max }+\beta\left(\underline{x}-m_{\max }-p \bar{x}-(1-p) \underline{x}+m_{\max }\right){ }^{2} 2\right)
\end{aligned}
$$

The strategy $\bar{m}_{5}=m_{\max }$ is optimal for the manager if (52) is larger than (48), (49), (50) and (51). We derive conditions on $\theta$ depending on the parameters $p$, $\delta$ and $\beta$ for which this is true and represent them as manifolds in the following figure.

Figure 9: Restrictions on $\theta$ satisfying the equilibrium conditions for the case $x_{t}=\bar{x}$

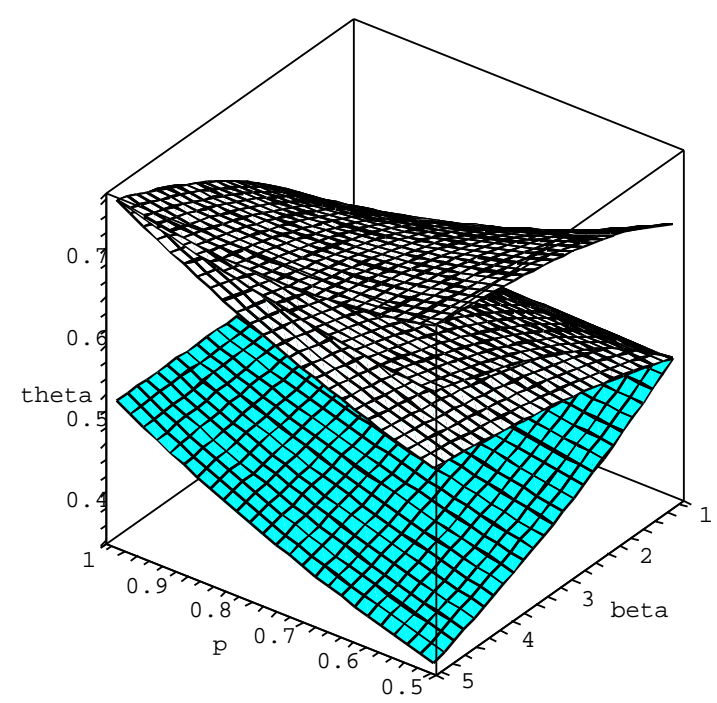

The two-dimensional manifolds determine the subsets of parameters for which certain payoffs are equal. The subset of parameters under the top manifold is such that (52) is larger than (50). The subset of parameters under the next two manifolds is such that (52) is larger than (48) respectively (49). The subset of parameters under the last manifold is such that (52) is larger than (51).

As one can easily see in the figure above only condition (51) is binding so that the upper bound is determined by the condition that (52) is larger than (51). This is true for $\theta \in\left[0, \frac{2}{2+\delta(1+p)+\delta \beta(1-p)}\right)$. 
The condition on $\theta$ for which the manager follows $\underline{m}=m_{\max }$ achieve the highest utility is not binding.

Suppose now that the best forecasts of the analysts in the second equilibrium are $F_{t}^{*}=p \bar{x}+(1-p) \underline{x}+m_{m i n}$ and $\bar{F}_{t+1}^{*}=\underline{F}_{t+1}^{*}=p \bar{x}+(1-p) \underline{x}-m_{m i n}$. Later on, we are proving this.

Given the analysts' forecasts, the manager can chose between the following strategies:

$$
\begin{aligned}
& \underline{m}_{1}=m_{\min } \\
& \underline{m}_{2}=m_{\min }+\bar{x}-p \bar{x}-(1-p) \underline{x} \\
& \underline{m}_{3}=m_{\min }-\underline{x}+p \bar{x}+(1-p) \underline{x} \\
& \underline{m}_{4}=0 \\
& \underline{m}_{5}=m_{\max }
\end{aligned}
$$

respectively

$$
\begin{aligned}
& \bar{m}_{1}=m_{\min } \\
& \bar{m}_{2}=m_{\min }+\bar{x}-p \bar{x}-(1-p) \underline{x} \\
& \bar{m}_{3}=0 \\
& \underline{m}_{4}=m_{\max }
\end{aligned}
$$

Consider first the case where $x_{t}=\underline{x}$. The payoffs from following the strategies $\underline{m}_{1}$ to $\underline{m}_{5}$ are the following:

$$
\begin{aligned}
& \underline{u}_{1}^{M}(.)=(1-\theta)\left[\underline{x}+m_{\text {min }}+\delta\left(p \bar{x}+(1-p) \underline{x}-m_{\text {min }}\right)\right. \\
& \left.+\beta\left(\underline{x}+m_{\min }-p \bar{x}-(1-p) \underline{x}-m_{\text {min }}\right)\right] \\
& +\delta \theta p\left[\bar{x}-m_{\text {min }}+\bar{x}-m_{m i n}-p \bar{x}-(1-p) \underline{x}+m_{m i n}\right] \\
& +\delta \theta(1-p)\left[\underline{x}-m_{\min }+\beta\left(\underline{x}-m_{\min }-p \bar{x}-(1-p) \underline{x}+m_{\min } \chi \overline{5} 3\right)\right. \\
& \underline{u}_{2}^{M}(.)=(1-\theta)\left[\underline{x}+m_{\text {min }}+\bar{x}-p \bar{x}-(1-p) \underline{x}+\delta\left(p \bar{x}+(1-p) \underline{x}-m_{\text {min }}\right)\right. \\
& \left.+\beta\left(\underline{x}+m_{\min }+\bar{x}-p \bar{x}-(1-p) \underline{x}-p \bar{x}-(1-p) \underline{x}-m_{\min }\right)\right] \\
& +\delta \theta p\left[\bar{x}-m_{\min }-\bar{x}+p \bar{x}+(1-p) \underline{x}\right] \\
& +\delta \theta(1-p)\left[\underline{x}-m_{\text {min }}-\underline{x}+p \bar{x}+(1-p) \underline{x}\right. \\
& \left.+\beta\left(\underline{x}-m_{\min }-\bar{x}+p \bar{x}+(1-p) \underline{x}-p \bar{x}-(1-p) \underline{x}+m_{m i n}\right)\right] \\
& \underline{u}_{3}^{M}(.)=(1-\theta)\left[\underline{x}+m_{\text {min }}-\underline{x}+p \bar{x}+(1-p) \underline{x}+\delta\left(p \bar{x}+(1-p) \underline{x}-m_{m i n}\right)\right] \\
& +\delta \theta p\left[\bar{x}+\underline{x}-p \bar{x}-(1-p) \underline{x}+m_{\min }\right. \\
& \left.+\beta\left(\bar{x}+\underline{x}-p \bar{x}-(1-p) \underline{x}+m_{\text {min }}-p \bar{x}-(1-p) \underline{x}+m_{m i n}\right)\right] \\
& +\delta \theta(1-p)\left[\underline{x}-+\underline{x}-p \bar{x}-(1-p) \underline{x}+m_{\min }\right. \\
& \left.+\beta\left(\underline{x}+\underline{x}-p \bar{x}-(1-p) \underline{x}+m_{m i n}-p \bar{x}-(1-p) \underline{x}+m_{m i n}\right)\right]
\end{aligned}
$$




$$
\begin{aligned}
& \underline{u}_{4}^{M}(.)=(1-\theta)\left[\underline{x}+\delta\left(p \bar{x}+(1-p) \underline{x}-m_{\text {min }}\right)\right. \\
&\left.+\underline{x}-p \bar{x}-(1-p) \underline{x}-m_{\text {min }}\right] \\
&+\delta \theta p\left[\bar{x}+\beta\left(\bar{x}-p \bar{x}-(1-p) \underline{x}+m_{\min }\right]\right. \\
&+\delta \theta(1-p)\left[\underline{x}-m_{\min }+\beta\left(\underline{x}-p \bar{x}-(1-p) \underline{x}+m_{\min }\right)\right] \quad \text { (56) } \\
& \\
& \underline{u}_{5}^{M}(.)=\quad(1-\theta)\left[\underline{x}+m_{\max }+\delta\left(p \bar{x}+(1-p) \underline{x}-m_{\min }\right)\right. \\
&\left.+\underline{x}+m_{\max }-p \bar{x}-(1-p) \underline{x}-m_{\min }\right] \\
&+\delta \theta p\left[\bar{x}-m_{\max }+\beta\left(\bar{x}-m_{\max }-p \bar{x}-(1-p) \underline{x}+m_{\min }\right)\right] \\
&+ \delta \theta(1-p)\left[\underline{x}-m_{\max }+\beta\left(\underline{x}-m_{\max }-p \bar{x}-(1-p) \underline{x}+m_{\min }(0 \bar{j} 7)\right.\right.
\end{aligned}
$$

The strategy $\underline{m}=m_{\min }$ is optimal for the manager, if the payoff $(53)$ is larger than the payoffs (54), (55), (56) and (57). We derive conditions on $\theta$ depending on the parameters $p, \beta$ and $\delta$ for which this is true and illustrate them in the following figure.

Figure 10: Restrictions on $\theta$ satisfying the equilibrium conditions for the case $x_{t}=\underline{x}$

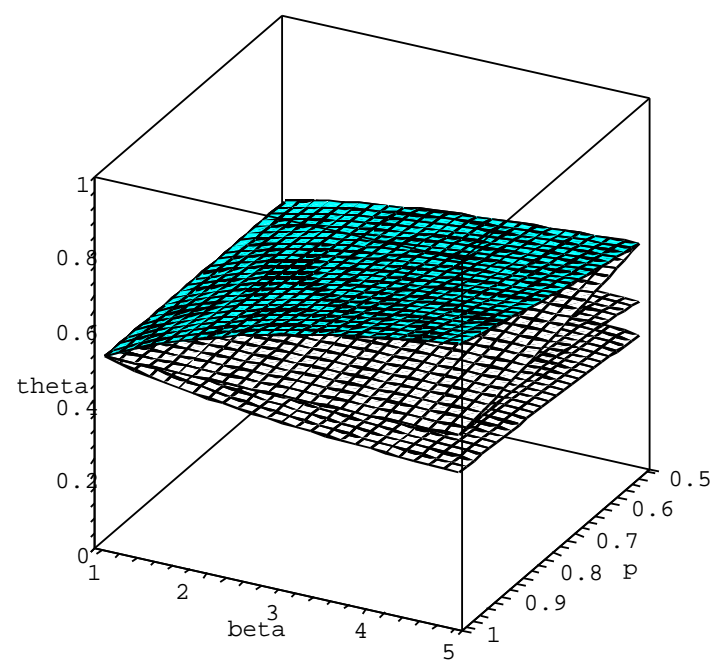

The manifolds determine the subsets of parameters for which certain payoffs are equal. The subset of parameters above the lowest manifold is such that (53) is larger than (57). The subset of parameters above the next two manifolds is such that (53) is larger than (56) respectively (55). The subset of parameters above the manifolds on the top is such that (53) is larger than (54).

As one can easily see in the figure above, the lower bound for the parameter $\theta$ is determined by the condition that (53) is larger than (54), which is true for $\theta \in\left(\frac{1+\beta}{(1+\beta)(1+\delta)+\delta p(1-\beta)}, 1\right]$. 
The manager's payoff is maximal if she decides to manipulate earnings down to $\underline{m}=m_{\min }$ if (53) is larger than (54). If this condition is satisfied, the manager would chose $\bar{m}=m_{\text {min }}$.

Given the manager's strategy $\underline{m}=\bar{m}=m_{\min }$ respectively $\underline{m}=\bar{m}=m_{\max }$ the best response of the analysts minimizing the squared mean forecast error as defined in (7) is:

$$
F_{t}^{*}=p \bar{x}+(1-p) \underline{x}+p \bar{n}^{*}+(1-p) \underline{n}^{*}=p \bar{x}+(1-p) \underline{x}+m_{\text {min }}
$$

respectively

$$
F_{t}^{*}=p \bar{x}+(1-p) \underline{x}+p \bar{n}^{*}+(1-p) \underline{n}^{*}=p \bar{x}+(1-p) \underline{x}+m_{\max }
$$

and

$$
F_{t+1}^{*}=p \bar{x}+(1-p) \underline{x}+\mu \bar{n}^{*}+(1-\mu) \underline{n}^{*}=p \bar{x}+(1-p) \underline{x}-m_{\min }
$$

respectively

$$
F_{t+1}^{*}=p \bar{x}+(1-p) \underline{x}+\mu \bar{n}^{*}+(1-\mu) \underline{n}^{*}=p \bar{x}+(1-p) \underline{x}-m_{\max }
$$

\section{A.4 Proof of Theorem 4}

If $v()=$.0 , the manager's payoffs in both states are:

$$
\begin{aligned}
\bar{u}^{M}(.)= & (1-\theta) \max \left(\bar{x}+\bar{m}+\delta F_{t+1}-X, 0\right) \\
& +\delta \theta p \max (\bar{x}-\bar{m}-X, 0) \\
& +\delta \theta(1-p) \max (\underline{x}-\bar{m}-X, 0)
\end{aligned}
$$

respectively

$$
\begin{aligned}
\underline{u}^{M}(.)= & (1-\theta) \max \left(\underline{x}+\underline{m}+\delta F_{t+1}-X, 0\right) \\
& +\delta \theta p \max (\bar{x}-\underline{m}-X, 0) \\
& +\delta \theta(1-p) \max (\underline{x}-\underline{m}-X, 0)
\end{aligned}
$$

where $X:=p \bar{x}+(1-p) \underline{x}$.

Consider first the case $x_{t}=\bar{x}$ where the manager aims to find some $\bar{m} \in$ $\left[m_{\text {min }}, m_{\text {max }}\right]$ that maximizes $(62)$ given $F_{t+1}$. Suppose that in this equilibrium $F_{t+1}^{*}=X=p \bar{x}+(1-p) \underline{x}$. Then, the manager's marginal utility would change when the manager switches between the following strategies:

$$
\begin{aligned}
& \bar{m}_{1}=m_{\min } \\
& \bar{m}_{2}=\underline{x}-X \\
& \bar{m}_{3}=p \bar{x}+(1-p) \underline{x}-\bar{x} \\
& \bar{m}_{4}=X-\delta(\bar{x}+(1-p) \underline{x})-\bar{x} \\
& \bar{m}_{5}=0 \\
& \bar{m}_{6}=\bar{x}-X \\
& \bar{m}_{7}=m_{\max }
\end{aligned}
$$


The value of the call options in period $t$ and $t+1$ associated with these strategies is given in the following table.

\begin{tabular}{c|c|c|c} 
& $\bar{C}_{t}$ & $\bar{C}_{t+1}$ & $\underline{C}_{t+1}$ \\
\hline $\bar{m}_{1}$ & 0 & $(1-p)(\bar{x}-\underline{x})-m_{\min }$ & $-p(\bar{x}-\underline{x})-m_{\text {min }}$ \\
$\bar{m}_{2}$ & 0 & $\bar{x}-\underline{x}$ & 0 \\
$\bar{m}_{3}$ & $\delta X$ & $2(1-p)(\bar{x}-\underline{x})$ & 0 \\
$\bar{m}_{4}$ & 0 & $2(1-p)(\bar{x}-\underline{x})+\delta X$ & 0 \\
$\bar{m}_{5}$ & $(1-p)(\bar{x}-\underline{x})+\delta X$ & $(1-p)(\bar{x}-\underline{x})$ & 0 \\
$\bar{m}_{6}$ & $2(1-p)(\bar{x}-\underline{x})+\delta X$ & 0 & 0 \\
$\bar{m}_{7}$ & $(1-p)(\bar{x}-\underline{x})+\delta X+m_{\max }$ & 0 & 0
\end{tabular}

The strategies $\bar{m}_{3}$ and $\bar{m}_{5}$, which are consistent with the analysts' expectations are both dominated strategies. Thus, given the analysts' beliefs $F_{t+1}=X=p \bar{x}+(1-p) \underline{x}$, the manager is always better off if she deviates from the strategy consistent with these beliefs. In particular, the manager's utility is maximal if she follow either strategy $\bar{m}_{1}=m_{\min }$ or strategy $\bar{m}_{7}=m_{\max }$ in dependance on the parameter of the utility function, i.e. $\delta$ and $\theta$.

Consider next the case $x_{t}=\underline{x}$ where the manager aims to find some $\bar{m} \in$ $\left[m_{\min }, m_{\max }\right]$ that maximizes $(6 \overline{3})$ given $F_{t+1}=X=p \bar{x}+(1-p) \underline{x}$. Then, the manager's utility would change when the manager switches between the following strategies:

$$
\begin{aligned}
& \underline{m}_{1}=m_{\min } \\
& \underline{m}_{2}=\underline{x}-X \\
& \underline{m}_{3}=0 \\
& \underline{m}_{4}=\bar{x}-X \\
& \underline{m}_{5}=X-\delta(p \bar{x}+(1-p) \underline{x})-\underline{x} \\
& \underline{m}_{6}=p \bar{x}+(1-p) \underline{x}-\underline{x} \\
& \underline{m}_{7}=m_{\max }
\end{aligned}
$$

The value of the call options in period $t$ and $t+1$ associated with these strategies is given in the following table.

\begin{tabular}{c|c|c|c} 
& $\underline{C}_{t}$ & $\bar{C}_{t+1}$ & $\underline{C}_{t+1}$ \\
\hline$\underline{m}_{1}$ & 0 & $(1-p)(\bar{x}-\underline{x})-m_{\min }$ & $-p(\bar{x}-\underline{x})-m_{\text {min }}$ \\
$\underline{m}_{2}$ & 0 & $\bar{x}-\underline{x}$ & 0 \\
$\underline{m}_{3}$ & 0 & $(1-p)(\bar{x}-\underline{x})$ & 0 \\
$\underline{m}_{4}$ & 0 & 0 & 0 \\
$\underline{m}_{5}$ & 0 & 0 & 0 \\
$\underline{m}_{6}$ & $\delta X$ & 0 & 0 \\
$\underline{m}_{7}$ & $-p(\bar{x}-\underline{x})+\delta X+m_{\max }$ & 0 & 0
\end{tabular}

Thus, the strategies $\underline{m}_{6}$ and $\underline{m}_{3}$ consistent with the analysts' beliefs are both dominated strategies. Thus, given the analysts' beliefs $F_{t+1}=X=p \bar{x}+(1-p) \underline{x}$, the manager is always better if she deviate from the strategies consistent with these beliefs. In particular, the manager's utility is maximal if she follows either strategy $\bar{m}_{1}=m_{\min }$ or strategy $\bar{m}_{7}=m_{\max }$ in dependance on the parameter $\delta$ and $\theta$. 
If the manager chooses to play $\bar{m}=\underline{m}=m_{\min }$ or $\bar{m}=\underline{m}=m_{\max }$ the analysts would change their beliefs in equilibrium so that $F_{t+1}=p \bar{x}+(1-$ $p) \underline{x}-m_{\min }$ respectively $F_{t+1}=p \bar{x}+(1-p) \underline{x}-m_{\max }$.

Consider first the case where $F_{t+1}=p \bar{x}+(1-p) \underline{x}-m_{\min }$. This is an equilibrium strategy if the manager prefers to play $\bar{m}=\underline{m}=m_{\min }$ to any other strategy. In order to derive conditions for which this is true we evaluate the value of the stock options in both periods associated with the different manipulation strategies available to the manager given that $F_{t+1}=p \bar{x}+(1-p) \underline{x}-m_{\text {min }}$. The strategies available to the manager are:

$$
\begin{aligned}
& \bar{m}_{1}=m_{\min } \\
& \bar{m}_{2}=\underline{x}-X \\
& \bar{m}_{3}=0 \\
& \bar{m}_{4}=\bar{x}-X \\
& \bar{m}_{5}=m_{\max }
\end{aligned}
$$

respectively

$$
\begin{aligned}
& \underline{m}_{1}=m_{\min } \\
& \underline{m}_{2}=\underline{x}-X \\
& \underline{m}_{3}=0 \\
& \underline{m}_{4}=\bar{x}-X \\
& \underline{m}_{5}=m_{\max }
\end{aligned}
$$

The following table summarizes the value of the stock options in both periods associated with these strategies.

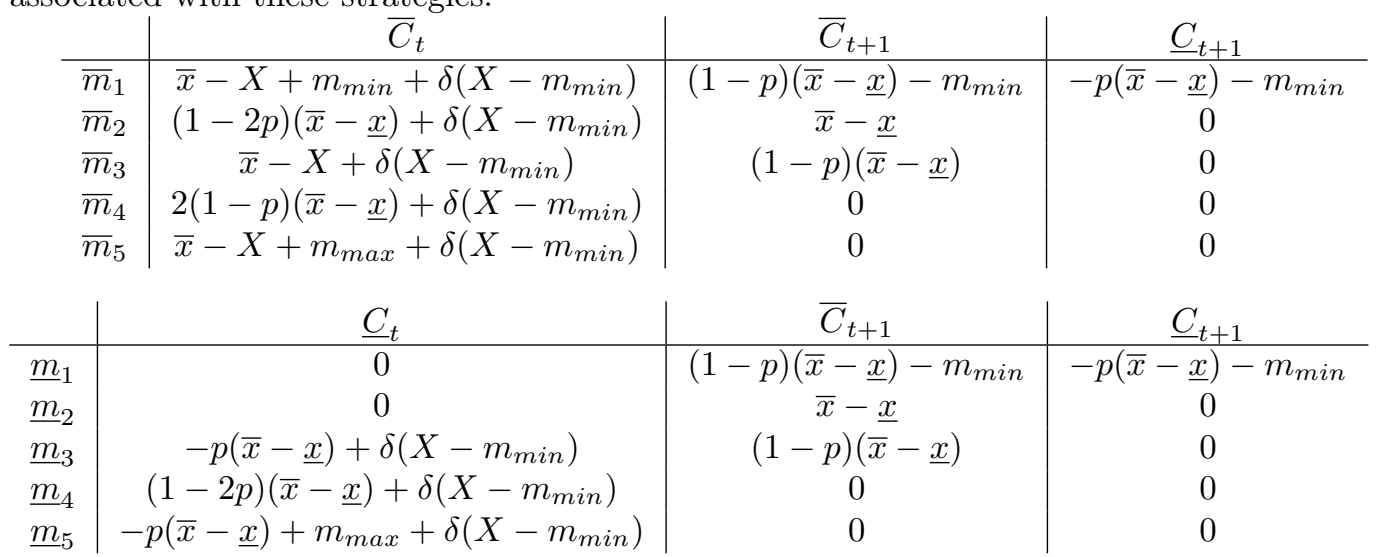

where $X:=p \bar{x}+(1-p) \underline{x}$. The next figure illustrates for which parameters $\theta, p$, and $\delta$ the manager's payoff is maximal if she choosees the strategy $\bar{m}_{1}=$ $m_{\text {min }}$. 
Figure 11: Restrictions on $\theta$ satisfying the equilibrium conditions for the case $x_{t}=\bar{x}$ given that $F_{t+1}=p \bar{x}+(1-p) \underline{x}-m_{\min }$

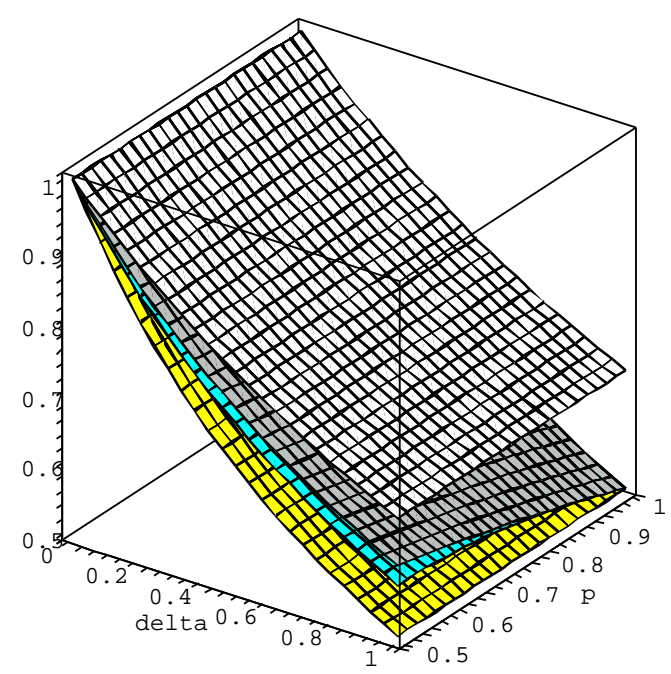

The manifolds determine the subsets of parameters for which certain payoffs are equal. The subset of parameters above the lowest manifold is such that $\bar{u}^{M}\left(\bar{m}_{1}\right)>\bar{u}^{M}\left(\bar{m}_{2}\right)$. The subset of parameters above the next two manifolds is such that $\bar{u}^{M}\left(\bar{m}_{1}\right)>\bar{u}^{M}\left(\bar{m}_{3}\right)$ and $\bar{u}^{M}\left(\bar{m}_{1}\right)>\bar{u}^{M}\left(\bar{m}_{4}\right)$. The subset of parameters above the manifolds on the top is such that $\bar{u}^{M}\left(\bar{m}_{1}\right)>\bar{u}^{M}\left(\bar{m}_{5}\right)$.

Thus, given that $F_{t+1}=p \bar{x}+(1-p) \underline{x}-m_{\min }$ the manager chooses $\bar{m}=m_{\min }$ if $\bar{u}^{M}\left(\bar{m}_{1}\right)>\bar{u}^{M}\left(\bar{m}_{5}\right)$, which is true for

$$
\theta>\frac{2}{2+\delta}
$$

If condition (64) holds, the manager would also choose $\underline{m}_{1}=m_{\min }$ since $\underline{u}^{M}\left(\underline{m}_{1}\right)>\underline{u}^{M}(\underline{m})$ for any $p \in[0,1]$ and $\delta \in[0,1]$. This is illustrated in the following figure. 
Figure 12: Restrictions on $\theta$ for which $\bar{u}^{M}\left(\bar{m}_{1}\right)>\bar{u}^{M}\left(\bar{m}_{5}\right)$ and $\underline{u}^{M}\left(\underline{m}_{1}\right)>$ $\underline{u}^{M}\left(\bar{m}_{5}\right)$ given that $F_{t+1}=p \bar{x}+(1-p) \underline{x}-m_{\text {min }}$

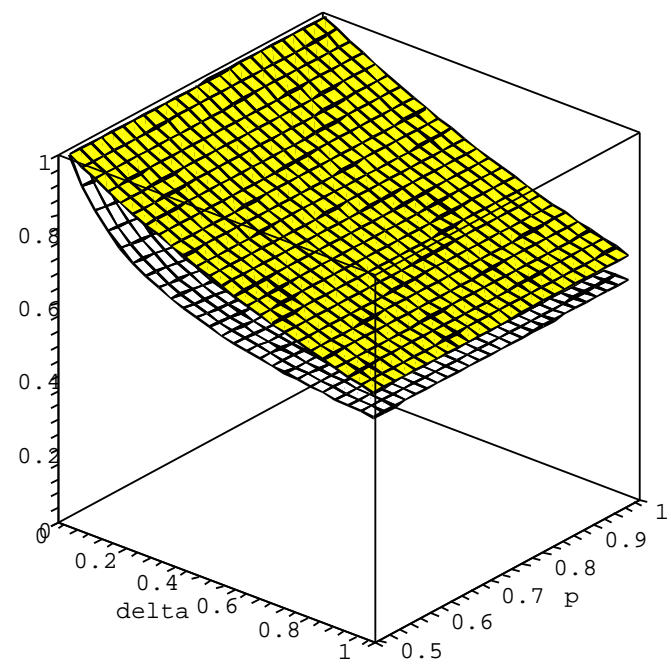

The manifolds determine the subsets of parameters for which certain payoffs are equal. The subset of parameters above the lowest manifold is such that $\underline{u}^{M}\left(\bar{m}_{1}\right)$ is maximal. The subset of parameters above the manifolds on the top is such that $\bar{u}^{M}\left(\bar{m}_{1}\right)$ is maximal.

Consider now the case where $F_{t+1}=p \bar{x}+(1-p) \underline{x}-m_{\max }$. The manager can choose between the same manipulation strategies as in the case where $F_{t+1}=$ $p \bar{x}+(1-p) \underline{x}-m_{m i n}$. The value of her stock options changes as follows.

\begin{tabular}{c|c|c|c} 
& $\bar{C}_{t}$ & $\bar{C}_{t+1}$ & $\underline{C}_{t+1}$ \\
\hline $\bar{m}_{1}$ & 0 & $(1-p)(\bar{x}-\underline{x})-m_{\min }$ & $-p(\bar{x}-\underline{x})-m_{\min }$ \\
$\bar{m}_{2}$ & 0 & $\bar{x}-\underline{x}$ & 0 \\
$\bar{m}_{3}$ & $-p(\bar{x}-\underline{x})+\delta\left(X-m_{\max }\right)$ & $(1-p)(\bar{x}-\underline{x})$ & 0 \\
$\bar{m}_{4}$ & $2(1-p)(\bar{x}-\underline{x})+\delta\left(X-m_{\max }\right)$ & 0 & 0 \\
$\bar{m}_{5}$ & $(1-p)(\bar{x}-\underline{x})+\delta\left(X-m_{\max }\right)+m_{\max }$ & 0 & 0
\end{tabular}

\begin{tabular}{c|c|c|c} 
& $\underline{C}_{t}$ & $\bar{C}_{t+1}$ & $\underline{C}_{t+1}$ \\
\hline$\underline{m}_{1}$ & 0 & $(1-p)(\bar{x}-\underline{x})-m_{\min }$ & $-p(\bar{x}-\underline{x})-m_{\min }$ \\
$\underline{m}_{2}$ & 0 & $\bar{x}-\underline{x}$ & 0 \\
$\underline{\underline{m}}_{3}$ & 0 & $(1-p)(\bar{x}-\underline{x})$ & 0 \\
$\underline{\underline{m}}_{4}$ & 0 & 0 & 0 \\
$\underline{\underline{x}}_{5}$ & $-p(\bar{x}-\underline{x})+m_{\max }+\delta\left(X-m_{\max }\right)$ & 0 & 0
\end{tabular}

for $\delta<\frac{2(p-1)}{2 p-3}$.

Thus, the manager chooses $\bar{m}=m_{\max }$ but also $\underline{m}=m_{\max }$ if $\underline{u}^{M}\left(\underline{m}_{5}\right)>$ $\underline{u}^{M}\left(\underline{m}_{1}\right)$. This is true for

$$
\theta<\frac{2(1-p)+\delta(2 p-3)}{2(1-p)+\delta(2 p-1)}
$$




\section{A.5 Proof of Theorem 5}

If $v() \neq$.0 the manager's payoffs in both states are:

$$
\begin{aligned}
\bar{u}^{M}(.)= & (1-\theta) \max \left[\bar{x}+\bar{m}+\delta \bar{F}_{t+1}+v\left(\bar{x}+\bar{m}-F_{t}\right)-X, 0\right] \\
& \delta \theta p \max \left[\bar{x}-\bar{m}+v\left(\bar{x}-\bar{m}-\bar{F}_{t+1}\right)-X, 0\right] \\
& +\delta \theta(1-p) \max \left[\underline{x}-\bar{m}+v\left(\underline{x}-\bar{m}-\bar{F}_{t+1}\right)-X, 0\right]
\end{aligned}
$$

and

$$
\begin{aligned}
\underline{u}^{M}(.)= & (1-\theta) \max \left[\underline{x}+\underline{m}+\delta \underline{F}_{t+1}+v\left(\underline{x}+\underline{m}-F_{t}\right)-X, 0\right] \\
& \delta \theta p \max \left[\bar{x}-\underline{m}+v\left(\bar{x}-\underline{m}-\underline{F}_{t+1}\right)-X, 0\right] \\
& +\delta \theta(1-p) \max \left[\underline{x}-\underline{m}+v\left(\underline{x}-\underline{m}-\underline{F}_{t+1}\right)-X, 0\right]
\end{aligned}
$$

where the function $v($.$) is defined as in (3) and X:=p \bar{x}+(1-p) \underline{x}$ as before.

Consider first the case where the manager aims to find some $\bar{m} \in\left[m_{\min }, m_{\max }\right]$ that maximizes $(66)$ given $\bar{F}_{t+1}$. Suppose that in equilibrium $\bar{F}_{t+1}^{*}=X=$ $p \bar{x}+(1-p) \underline{x}$. Then, the manager's marginal utility would change when the manager switches between the following strategies:

$$
\begin{aligned}
& \bar{m}_{1}=m_{\min } \\
& \bar{m}_{2}=\underline{x}-X=-p(\bar{x}-\underline{x}) \\
& \bar{m}_{3}=X-\bar{x}=-(1-p)(\bar{x}-\underline{x}) \\
& \bar{m}_{4}=0 \\
& \bar{m}_{5}=\bar{x}-X=(1-p)(\bar{x}-\underline{x}) \\
& \bar{m}_{6}=m_{\max }
\end{aligned}
$$

The value of the stock options in both periods associated with these strategies are given in the following table.

\begin{tabular}{c|c|c|c} 
& $\bar{C}_{t}$ & $\bar{C}_{t+1}$ & $\underline{C_{t+1}}$ \\
\hline $\bar{m}_{1}$ & 0 & $2(1-p)(\bar{x}-\underline{x})-2 m_{\min }$ & $-2 p(\bar{x}-\underline{x})-2 m_{\min }$ \\
$\bar{m}_{2}$ & 0 & $\bar{x}-\underline{x}$ & 0 \\
$\bar{m}_{3}$ & $2(1-p)(\bar{x}-\underline{x})+\delta X$ & $2(1-p)(\bar{x}-\underline{x})$ & 0 \\
$\bar{m}_{4}$ & $\delta X$ & $3(1-p)(\bar{x}-\underline{x})+\bar{x}$ & 0 \\
$\bar{m}_{5}$ & $4(1-p)(\bar{x}-\underline{x})+\delta X$ & 0 & 0 \\
$\bar{m}_{6}$ & $2(1-p)(\bar{x}-\underline{x})+2 m_{\max }+\delta X$ & 0 &
\end{tabular}

Thus, given that $F_{t}=\bar{F}_{t+1}=X=p \bar{x}-+(1-p) \underline{x}$ for any $\theta \in[0,1]$ the strategies $\bar{m}_{3}$ and $\bar{m}_{4}$, which are consistent with the analysts' forecasts are dominated. Moreover, if the analysts forecasts are $F_{t}=\bar{F}_{t+1}=X=$ $p \bar{x}+(1-p) \underline{x}$, the manager chooses either $\bar{m}_{1}=m_{\min }$ or $\bar{m}_{6}=m_{\max }$. Thus, in equilibrium the analysts would change their beliefs.

Suppose that the analysts best forecasts are $F_{t}=X+m_{\min }$ and $\bar{F}_{t+1}=$ $X-m_{\min }$. Then, the manager can choose among the following manipulation strategies:

$$
\begin{aligned}
& \bar{m}_{1}=m_{\min } \\
& \bar{m}_{2}=\bar{x}-X+m_{\min }=(1-p)(\bar{x}-\underline{x})+m_{\min } \\
& \bar{m}_{3}=0 \\
& \bar{m}_{4}=m_{\max }
\end{aligned}
$$


The value of the stock options in both periods associated with these strategies is summarized in the following table.

\begin{tabular}{c|c|c|c} 
& $\bar{C}_{t}$ & $\bar{C}_{t+1}$ & $\underline{C}_{t+1}$ \\
\hline $\bar{m}_{1}$ & $2(1-p)(\bar{x}-\underline{x})+\delta X+(1-\delta) m_{\min }$ & $2(1-p)(\bar{x}-\underline{x})-m_{\text {min }}$ & 0 \\
$\bar{m}_{2}$ & $4(1-p)(\bar{x}-\underline{x})+\delta X+(1-\delta) m_{\text {min }}$ & $-m_{\text {min }}$ & 0 \\
$\bar{m}_{3}$ & $2(1-p)(\bar{x}-\underline{x})+\delta X-(1+\delta) m_{\text {min }}$ & 0 & 0 \\
$\bar{m}_{4}$ & $2(1-p)(\bar{x}-\underline{x})+\delta X-(3+\delta) m_{\text {min }}$ & 0 & 0
\end{tabular}

The strategies $\bar{m}_{2}$ and $\bar{m}_{3}$ are dominated by $\bar{m}_{4}$ for any $\theta \in[0,1]$. Thus, given $F_{t}=X+m_{\min }$ and $\bar{F}_{t+1}=X-m_{m i n}$, the strategy $\bar{m}_{1}=m_{m i n}$ is an equilibrium strategy if $\bar{u}^{M}\left(\bar{m}_{1}\right) \geq u^{M}\left(\bar{m}_{4}\right)$. This is true for

$$
\theta \geq \frac{4}{4+3 \delta p-2 \delta p^{2}}
$$

If $x_{t}=\underline{x}$ the manager can choose among the following manipulation strategies:

$$
\begin{aligned}
& \underline{m}_{1}=m_{\min } \\
& \underline{m}_{2}=\underline{x}-X+m_{\min }=(1-p)(\bar{x}-\underline{x})+m_{\min } \\
& \underline{m}_{3}=X-\underline{x}+m_{\min }=p(\bar{x}-\underline{x})+m_{\min } \\
& \underline{m}_{4}=0 \\
& \underline{m}_{5}=m_{\max }
\end{aligned}
$$

The value of the stock options in both periods associated with these strategies is summarized in the following table.

\begin{tabular}{c|c|c|c} 
& $\underline{C}_{t}$ & $\bar{C}_{t+1}$ & $\underline{C}_{t+1}$ \\
\hline$\underline{m}_{1}$ & 0 & $2(1-p)(\bar{x}-\underline{x})-m_{\min }$ & 0 \\
$\underline{m}_{2}$ & 0 & $-m_{\min }$ & 0 \\
$\underline{m}_{3}$ & $\delta X+(1-\delta) m_{\min }$ & 0 & 0 \\
$\underline{m}_{4}$ & $\delta X-p(\bar{x}-\underline{x})-(1+\delta) m_{\min }$ & 0 & 0 \\
$\underline{m}_{5}$ & $\delta X-2 p(\bar{x}-\underline{x})+(3+\delta) m_{\max }$ & 0 & 0
\end{tabular}

for $\beta>\frac{2(1-p)}{2 p-1}$.

The strategy $\underline{m}_{1}=m_{\min }$ would be an equilibrium strategy of the manager if $\underline{u}^{M}\left(\underline{m}_{1}\right)$ is the maximum utility the manager can achieve given the forecasts of the analysts. Since the strategies $\underline{m}_{4}$ and $\underline{m}_{3}$ are dominated by $\underline{m}_{5}$ and the strategy $\underline{m}_{2}$ is dominated by $\underline{m}_{1}$ the strategy $\underline{m}_{1}$ is the best if $\underline{u}^{M}\left(\underline{m}_{1}\right)>$ $\underline{u}^{M}\left(\underline{m}_{5}\right)$ which is equivalent to $\theta>\frac{\underline{C}_{t}\left(\underline{m}_{5}\right)}{\delta p \bar{C}_{t+1}\left(\bar{m}_{1}\right)+\underline{C}_{t}\left(\underline{m}_{5}\right)}$. Recall that the condition (70) is equivalent to $\theta>\frac{\bar{C}_{t}\left(\bar{m}_{5}\right)-\bar{C}_{t}\left(\bar{m}_{1}\right)}{\delta p \bar{C}_{t+1}\left(\bar{m}_{1}\right)+\bar{C}_{t}\left(\bar{m}_{5}\right)-\bar{C}_{t}\left(\bar{m}_{1}\right)}$. Thus, if (70) holds, the condition $\theta>\frac{\underline{C}_{t}\left(\underline{m}_{5}\right)}{\delta p \bar{C}_{t+1}\left(\bar{m}_{1}\right)+\underline{C}_{t}\left(\underline{m}_{5}\right)}$ would not be binding since $\underline{C}_{t}\left(\underline{m}_{5}\right)<\bar{C}_{t}\left(\bar{m}_{5}\right)$.

Suppose now that the analysts' best forecasts are $F=p \bar{x}+(1-p) \underline{x}+m_{\max }$ and $F_{t+1}=p \bar{x}+(1-p) \underline{x}-m_{\max }$. This is an equilibrium strategy, if the manager would play $\bar{m}=\underline{m}=m_{\max }$. However, if investors are loss averse, i.e. $\beta>1$, the manager would never play $\underline{m}=m_{\max }$, since this is a dominated strategy. This is because $\underline{C}_{t}\left(\underline{m}=m_{\max }\right)>0$ only if $\beta<\frac{(1-\delta)\left(X-m_{\max }\right)-\underline{x}}{x-X}$. This condition is greater than 1 only if $\delta<\frac{m_{\max }-2(X-\underline{x}}{m_{m} a x-X}$, which is negative if we assume that $m_{\max }=\bar{x}-\underline{x}$. Thus, if investors are loss averse, i.e. $\beta>1$, the manager would 
never choose to play $\underline{m}=m_{\max }$ in equilibrium given that the analysts expect them to do so. Thus, this strategy is not part of the Bayesian Nash equilibrium (in pure strategies).

\section{A.6 Proof of Theorem 6}

The optimal forecasts of the guided analysts given their payoff function (7) with $\bar{n}=\bar{m}$ and $\underline{n}=\underline{m}$ are:

$$
F_{t}^{*}=p \bar{x}+(1-p) \underline{x}+p \bar{m}+(1-p) \underline{m}
$$

and

$$
F_{t+1}^{*}=p \bar{x}+(1-p) \underline{x}-\mu \bar{m}-(1-\mu) \underline{m}
$$

Given the best response of the analysts to the manager providing guidance with respect to the earnings she are about to shift over time, the manager's payoff in both states is:

$\bar{u}(.)^{M}=(1-\theta)[\bar{x}+\bar{m}+\delta(p \bar{x}+(1-p) \underline{x}-\mu \bar{m}-(1-\mu) \underline{m})]+\delta \theta p[\bar{x}-\bar{m}]+\delta \theta(1-p)[\underline{x}-\bar{m}]$

respectively

$\underline{u}(.)^{M}=(1-\theta)[\underline{x}+\underline{m}+\delta(p \bar{x}+(1-p) \underline{x}-\mu \bar{m}-(1-\mu) \underline{m})]+\delta \theta p[\bar{x}-\underline{m}]+\delta \theta(1-p)[\underline{x}-\underline{m}]$

Since $v()=$.0 the manager's payoff depends linearly on $\bar{m}$ respectively $\underline{m}$ so that the manager would either choose to play $m_{\max }$ or $m_{\min }$. If the manager choses the same action in both states, i.e. $\bar{m}=\underline{m} \in\left\{m_{\min }, m_{\max }\right\}$, the outsiders' beliefs $\mu$ do not matter and the manager's payoff is:

$$
\bar{u}(.)^{M}=(1-\theta)[\bar{x}+\bar{m}+\delta(p \bar{x}+(1-p) \underline{x}-\bar{m}]+\delta \theta p[\bar{x}-\bar{m}]+\delta \theta(1-p)[\underline{x}-\bar{m}]
$$

respectively

$$
\underline{u}(.)^{M}=(1-\theta)[\underline{x}+\underline{m}+\delta(p \bar{x}+(1-p) \underline{x}-\underline{m})]+\delta \theta p[\bar{x}-\underline{m}]+\delta \theta(1-p)[\underline{x}-\underline{m}]
$$

where

The manager would therefore prefer to manipulate the earnings rather than to report truthfully if either

$$
\theta<1-\delta \text { and } \bar{m}=m_{\max }>0
$$

or

$$
\theta>1-\delta \text { and } \bar{m}=m_{\min }<0
$$

If $\theta=1-\delta$, the manager is indifferent between earnings manipulation and truthful reporting. However, if the manager says that she is not going to manipulate the earnings and the analysts expect them to do so, they have strong incentives to deviate from the announced strategy. Thus, truthful reporting is not an equilibrium strategy for the manager guiding the analysts. Hence, a manager with $\theta=1-\delta$, would decide to manipulate earnings up, i.e. $\bar{m}=\underline{m}=m_{\max }$, since $1-\delta<\frac{1}{1+\delta}$ for any $0<\delta \leq 1$ and $\bar{m}=\underline{m}=m_{\max }$ is the optimal strategy of the manager with $\theta<\frac{1}{1+\delta}$. 


\section{A.7 Proof of Theorem 7}

The optimal forecasts of the analysts given their payoff function (7) with $\bar{n}=\bar{m}$ and $\underline{n}=\underline{m}$ are:

$$
\begin{gathered}
F_{t}^{*}=p \bar{x}+(1-p) \underline{x}+p \bar{m}+(1-p) \underline{m} \\
F_{t+1}^{*}=p \bar{x}+(1-p) \underline{x}-\mu \bar{m}-(1-\mu) \underline{m}
\end{gathered}
$$

Given the best response of the analysts to the manager guidance, the manager's payoffs are:

$$
\begin{aligned}
\bar{u}^{M}(.)= & (1-\theta) \max [\bar{x}+\bar{m}+\delta(p \bar{x}+(1-p) \underline{x}-\mu \bar{m}-(1-\mu) \underline{m})-X ; 0] \\
& +\delta \theta p \max [\bar{x}-\bar{m}-X ; 0] \\
& +\delta \theta(1-p) \max [\underline{x}-\bar{m}-X ; 0]
\end{aligned}
$$

respectively

$$
\begin{aligned}
\underline{u}^{M}(.)= & (1-\theta) \max [\underline{x}+\underline{m}+\delta(p \bar{x}+(1-p) \underline{x}-\mu \bar{m}-(1-\mu) \underline{m})-X ; 0] \\
& +\delta \theta p \max [\bar{x}-\underline{m}-X ; 0] \\
& +\delta \theta(1-p) \max [\underline{x}-\underline{m}-X ; 0]
\end{aligned}
$$

To determine the manager's optimal manipulation strategy while considering its impact on the best response of the analysts we consider different strategies. Given the manager's payoffs there are three reasonable candidates in both states, i.e. $\bar{m}_{1}=\underline{m}_{1}=m_{\min }, \bar{m}_{2}=\underline{m}_{2}=0$, or $\bar{m}_{3}=\underline{m}_{3}=m_{\max }$. If $x_{t}=\bar{x}$, the manager's call options have the following values:

\begin{tabular}{c|c|c|c} 
& $\bar{C}_{t}$ & $\bar{C}_{t+1}$ & $\underline{C_{t+1}}$ \\
\hline $\bar{m}_{1}$ & 0 & $(1-p)(\bar{x}-\underline{x})-m_{\min }$ & $-p(\bar{x}-\underline{x})-m_{\min }$ \\
$\bar{m}_{2}$ & $(1-p)(\bar{x}-\underline{x})+\delta X$ & $(1-p)(\bar{x}-\underline{x})$ & 0 \\
$\bar{m}_{3}$ & $(1-p)(\bar{x}-\underline{x})+(1-\delta) m_{\max }+\delta X$ & 0 & 0
\end{tabular}

Thus, the strategy $\bar{m}_{2}=0$ is a dominated strategy for any $\theta \in[0,1]$. The manager chooses $\bar{m}_{1}=m_{\min }$ if $\bar{u}^{M}\left(\bar{m}_{1}\right)>\bar{u}^{M}\left(\bar{m}_{3}\right)$, which is true for

$$
\theta>\frac{(2-p-\delta)(\bar{x}-\underline{x})+\delta X}{(2-p)(\bar{x}-\underline{x})+\delta X}
$$

Thus, if $\theta \in\left[0, \frac{(2-p-\delta)(\bar{x}-\underline{x})+\delta X}{(2-p)(\bar{x}-\underline{x})+\delta X}\right]$ the manager chooses $\bar{m}_{3}=m_{\max }$. If $x_{t}=\underline{x}$ the manager's call options have the following values.

\begin{tabular}{c|c|c|c} 
& $\underline{C}_{t}$ & $\bar{C}_{t+1}$ & $\underline{C}_{t+1}$ \\
\hline$\underline{m}_{1}$ & 0 & $(1-p)(\bar{x}-\underline{x})-m_{\min }$ & $-p(\bar{x}-\underline{x})-m_{\min }$ \\
$\underline{m}_{2}$ & 0 & $(1-p)(\bar{x}-\underline{x})$ & 0 \\
$\underline{m}_{3}$ & $-p(\bar{x}-\underline{x})+m_{\max }(1-\delta)+\delta X$ & 0 & 0
\end{tabular}

for $\delta<\frac{2 p-2}{2 p-3}$

The manager chooses the strategy $\underline{m}_{3}=m_{\max }$ if $\theta<\frac{\underline{C}_{t}\left(\underline{m}_{3}\right)}{\underline{\underline{\underline{m}}}_{t}\left(\underline{\underline{m}}_{3}\right)-\delta m_{\min }}$, which is equivalent to the condition (65). 